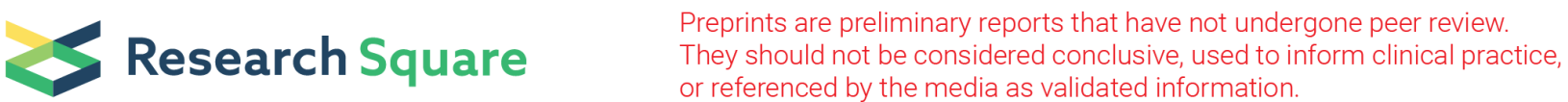 \\ Effect of SWCNT Volume Fraction on The Viscosity of Water Based Nanofluids
}

Hossein Namarvari ( $\square$ b.namarvari@yahoo.com )

Azarbaijan Shahid Madani University https://orcid.org/0000-0002-4123-7448

Naiyer Razmara

Azarbaijan Shahid Madani University

Caetano Rodrigues Miranda

University of Sao Paulo

\section{Research Article}

Keywords: Nanotubes, Viscosity, Nanofluids, Molecular Dynamics, Volume Fraction

Posted Date: March 9th, 2021

DOI: https://doi.org/10.21203/rs.3.rs-185965/v1

License: (1) This work is licensed under a Creative Commons Attribution 4.0 International License.

Read Full License

Version of Record: A version of this preprint was published at Journal of Molecular Modeling on August

17th, 2021. See the published version at https://doi.org/10.1007/s00894-021-04856-4. 


\title{
Effect of SWCNT Volume Fraction on the Viscosity of Water based Nanofluids
}

\author{
Hossein Namarvari $^{*}$, Naiyer Razmara ${ }^{1,2}$, Caetano Rodrigues Miranda ${ }^{2}$, Mir Yousef Hashemi ${ }^{1}$ \\ ${ }^{1}$ Department of Mechanical Engineering, Azarbaijan Shahid Madani University, Tabriz, Iran \\ ${ }^{2}$ Department of Mechanical Engineering, Escola Politécnica, University of São Paulo, São Paulo, SP, Brazil \\ *Correspondence author: Zip Code: 51559-34757 Fax: +98 4135234812 \\ Email: h.namarvari@azaruniv.ac.ir
}

\begin{abstract}
:
Nanofluids have drawn special attention during the last decades due to their various unique properties. It is revealed that the addition of nanotubes to the base materials can significantly change their properties. In the present work, the viscosity of water containing nanotube is calculated using the Molecular Dynamics Simulation for different volume fractions in the range between $0.557 \%$ and $3 \%$ at two temperatures (298K and $313 \mathrm{~K})$. The Green-Kubo equilibrium method is applied for calculating viscosity. The studied nanotube is an Armchair $(6,6)$ single-walled carbon nanotube. The results show the potential of the Molecular Dynamics Simulation technique as a powerful tool in the prediction of nanofluid properties beside the experimental results. A new relationship for viscosity is offered for volume fractions of $\phi \leq 3 \%$, according to the obtained results.
\end{abstract}

Keywords: Nanotubes, Viscosity, Nanofluids, Molecular Dynamics, Volume Fraction.

\section{Introduction}

Scientists have discovered that the existence of solid nanometer-sized particles in the base fluid would have changed significantly its transitional properties such as heat transfer and viscosity. Adding nanoparticles to the base fluid to change its properties is currently more common than adding particles which are in a larger size for shrinking the suspensions' instability. Furthermore, nanoparticles' importance and usage, especially nanotubes in different sciences lead researchers to struggle to expose their manner in distinctive conditions. In the past, studying on molecules were a difficult and exhausting try; researchers had to have done experimental works to find out the phenomena; but it's taken too much time and expenses; till the computer simulation was started and brought revolution to the science to save time and money, furthermore applied it in the Molecular Dynamic Simulation (MDS) 
as well [1]. The MDS has been evolving so fast over the course of last decades. In this investigation, this familiar method is used. Features at the nanoscale have an obvious contrast with those at macroscale; thus, a bit different formula and rules are used in the MD. Nanotubes invention discovered a new route for scientists to evolve technology faster. Their desire to apply this new high-tech invention in the industry makes them come up with new forms of nanotubes and never look back since the MDS and experiments accompany each other. There are different types of nanotubes, such as carbon nanotubes (CNTs), boron-nitride nanotubes (BNNTs); or they can be categorized as a single-wall or multi-wall nanotubes; so, their properties must be revealed. Leong et al. [2] performed studies on the viscosity characteristic of CNT in the presence of different surfactants for a wide range of weight percentages of nanoparticles. The results revealed that nanofluids with surfactant have less viscosity as compared with nanofluids without it. Furthermore, the increment in weight percentage of nanoparticles causes an increase in viscosity. Halelfadl et al. [3] have done an experimental research on nanofluids including MWCNTs dispersed in water. They have considered the effects of nanotubes on the viscosity of nanofluid in a variety of temperatures and volume fractions of the particle. It has been discovered that the nanofluids behave in the Newtonian manner for lower particle content. It has been also found that the nanofluids' viscosity does not change significantly with temperature for high shear rates. Hemmat et al.[4][5] have done studies on the thermal conductivity of the $\mathrm{Si}_{2} \mathrm{O}-\mathrm{MWCNT}$ and $\mathrm{Al}_{2} \mathrm{O}_{3}$ SWCNT in the based fluid, ethylene glycol; also, for $\mathrm{Si}_{2} \mathrm{O}-\mathrm{MWCNT}$ they have investigated its cost performance for industrial applications. The MDS was employed by Kuang et al.[6] to investigate on self-assembly of different cases of BNNTs and CNTs. immobilization into nanofluids which influenced by increasing at equivalent nanoparticle radius. Golberg et al. [7] have prepared a review article which obtained various information of BNNTs properties and dependent articles. Investigations on water flowed in an SWCNT at a wide range of diameters have been done by Zhang et al. [8]. They applied numerical analysis to explore the dependency of viscosity on the temperature and potential energy. The results showed acceptable agreement with the experimental viscosity of water at high pressure. Also, the results showed that the viscosity increases nonlinearly due to the increment of the diameter of SWCNTs. Finally, a semi-empirical formulation was suggested to calculate the viscosity of water inside SWCNTs. SWCNTs distributed in lube oil cuts nanofluids were investigated by Vakili-Nezhaad and Dorany [9] in different weight fractions, temperatures, and lengths of the nanotube. Murshed et al. [10] indicated that the nanofluids' viscosity increases by increasing the volume fractions of nanoparticles or by decreasing temperature. This research is based on 
nanofluids with spherical and cylindrical nanoparticles. Lu et al. [11] used MDS for calculating the viscosity of gold-water nanofluids. The nanofluid viscosity increased as a result of nanoparticle immobilization into nanofluids which influenced by increasing the equivalent nanoparticle radius. Ravisankar and Chand [12] prepared a literature review for most relevant experimental results about viscosity and thermal conductivity of several nanofluids. In the most cases, base fluids and nanofluids' viscosity and thermal conductivity compared with each other and revealed their connections; also, it has explored that there is no generalized correlation for applying it to all sorts of nanofluids. In the end, they offered to pay special attention to developing accurate theories for calculating nanofluids' properties. Regretfully there are few types of research that employed MDS for exposing viscosity of CNTs which dispersed in a base fluid. In spite of this, at the present article, the MDS method will be applied for assessment of volume concentrations and temperature impact on the viscosity of CNT-water nanofluid due to the fact, this study can be considered as a novelty of this study. It is going to be done by LAMMPS, which is an open-source molecular simulation package [13]. The nanofluid whose viscosity is to be evaluated, is regarded as a dispersion of SWCNT in pure water with different volume fractions at two temperatures (298K and $313 \mathrm{~K}$ ). The liquid water molecules interaction model is supposed to follow the TIP4P model. The interactions of the CNT atoms are established by Tersoff potential and the interactions between carbon atoms and water molecules are simulated by Lennard-Jones potential.

\section{SIMULATION TECHNIQUE}

MDS is used for simulating the typical nanofluid; MDS is a method that link theory and experiment for detecting properties of atoms and molecules such as thermal conductivity, diffusion, viscosity and etc. Also progressing in MDS and technology provide some ways to simulate systems on a larger scale with much more atmos. For calculating the viscosity of a liquid, MDS offers several methods. The equilibrium molecular dynamics (EMD) and the non-equilibrium molecular dynamics (NEMD) [14]. Sometimes, EMD approach in contrast with NEMD will be able to converge with difficulty; Guo et al. [15] and Chen et al. [16] sought to overcome this flaw by adopting enough statistics with careful integration time's technique. On the other hand, the EMD method is able to calculate different properties for same state point at the same time in a single simulation run, nevertheless, NEMD method doesn't have this option[17]. In this work, the EMD approach is used to compute the viscosity of dispersed carbon nanotube in the water. Green-Kubo formula is applied to estimate nanofluid's viscosity in this article as well as lots of researches that used this theory 
for computing thermodynamic properties (see e.g.,[18][19][20]). MDS is based on Newton's second law $\left(F=\sum M a\right)$ and the interatomic forces are obtained by the atomic potential. Hence, the most sensitive part of each simulation with MD is the atomic potential for interactions between components. Each simulation in MDS begins with the simulating box of the system and its contents. For this purpose, VMD software[21] is applied to make a box of pure water with TIP4P structure (Figure. 1-A) and an armchair carbon nanotube, type $(6,6)$ at length of $3 \mathrm{~nm}$ (Figure. 1-B). Then, CNT is dispersed in the pure water (Figure. 1-C).

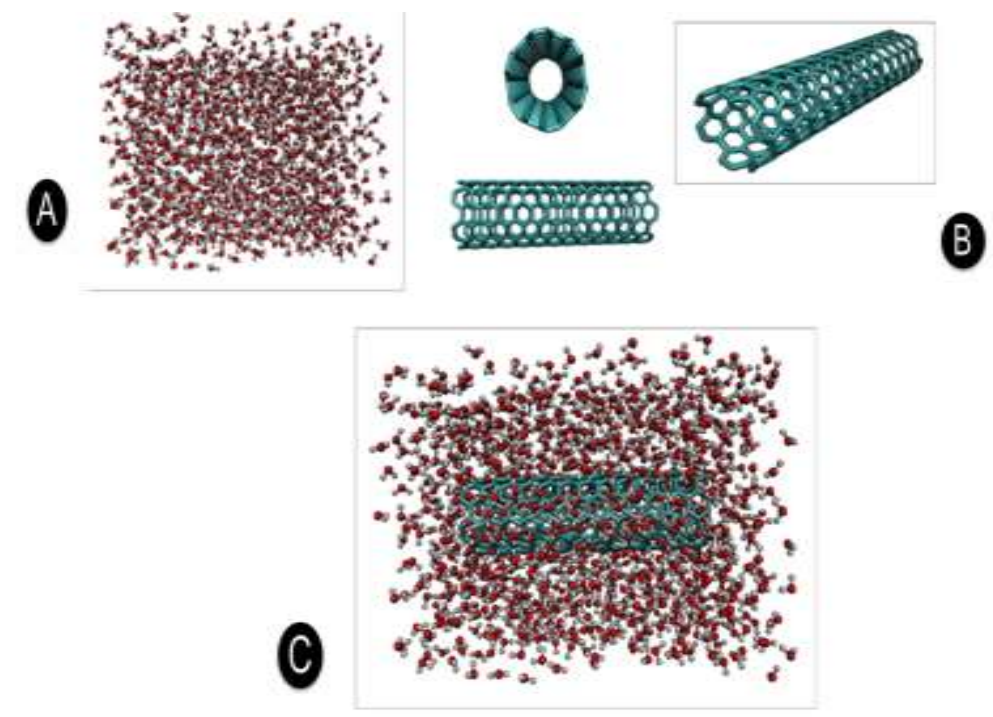

Figure 1. Pure water structure (A) - Carbon Nanotube structure (B) - Carbon Nanotube is dispersed in pure water.

The main features of water TIP4P structure are shown in figure 2 , and the value of its parameters are tabulated in Table 1[22]:

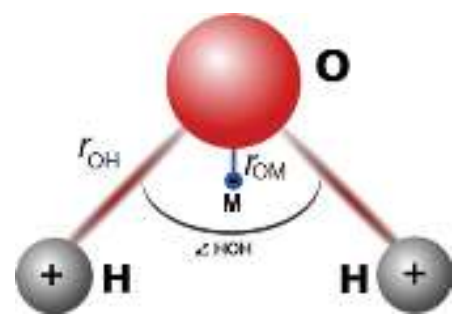

Figure 2. Schematic of TIP4P water model.

The 12-6 Lennard-Jones potential describes the interactions between CNT and water's molecules.

$\varphi_{L J}(\mathrm{r})=4 \epsilon\left[(\sigma / r)^{12}-(\sigma / r)^{6}\right]$

where $\sigma$ is the effective diameter of molecules, $\varepsilon$ is the potential well depth, and $r=\left|r_{i}-r_{j}\right|$ is the distance between molecules $i$ and $j$. Tersoff potential models the interactions between carbon atoms[23]: 


$$
E=\frac{1}{2} \sum \sum V_{i j}
$$

$V_{i j}=\mathcal{F}_{C}\left(r_{i j}\right)\left[\mathcal{F}_{R}\left(r_{i j}\right)+b_{i j} \mathcal{F}_{A}\left(r_{i j}\right)\right.$

$\mathcal{F}_{R}(\mathrm{r})=-\operatorname{Aexp}\left(-\lambda_{1} \mathrm{r}\right)$

$\mathcal{F}_{A}(\mathrm{r})=-\operatorname{Bexp}\left(-\lambda_{2} \mathrm{r}\right)$

$\mathcal{F}_{C}(\mathrm{r})= \begin{cases}1 & : \mathrm{r}<\mathrm{R}-\mathrm{D} \\ \frac{1}{2}-\frac{1}{2} \sin \left(\frac{\pi}{2} \frac{r-R}{D}\right) & : \quad \quad \quad R-D<r \\ 0 & : \quad r>R+D\end{cases}$

$b_{i j}=\left(1+\beta^{n} \zeta_{i j}^{n}\right)^{\frac{-1}{2 n}}$

$\zeta_{i j}=\sum_{k \neq i j} \mathcal{F}_{C}\left(r_{i k}\right) \mathrm{g}\left(\theta_{i j k}\right) \exp \left[\lambda_{3}^{m}\left(r_{i j}-r_{i k}\right)^{m}\right]$

$\mathrm{g}(\theta)=\Upsilon_{i j k}\left(1+\frac{c^{2}}{d^{2}}-\frac{c^{2}}{\left[d^{2}+\left(\cos \theta-\cos \theta_{0}\right)^{2}\right]}\right)$

where $\mathcal{F}_{R}$ is a two-body expression and $\mathcal{F}_{A}$ includes three-body interactions. The sums in the formula are over all neighbors $J$ and $K$ of atom $I$ within a cutoff distance $=R+D$. The $n, \beta$, $\lambda_{2}, B, \lambda_{1}$, and $A$ parameters are just utilized for two-body interactions. The $m, \Upsilon, \lambda_{3}, c, d$, and $\cos \theta_{0}$ parameters are just utilized for three-body interactions. The $R$ and $D$ parameters are used for both two-body and three-body interactions. The value of $m$ must be 3 or 1 [13]. The parameters for the 12-6 Lennard-Jones potential for Carbon is tabulated in Table 2 $[24][1]$.

Table 1. The structural properties and parameters used in the TIP4P water model

\begin{tabular}{cc}
\hline Parameters & Value \\
\hline O mass & $15.9994 / \mathrm{g} \mathrm{mol}^{-1}$ \\
H mass & $1.008 / \mathrm{g} \mathrm{mol}^{-1}$ \\
O charge & $-1.040(\mathrm{e})$ \\
H charge & $+0.520(\mathrm{e})$ \\
OH bond & $0.9572 / \AA$ \\
HOH angle & $104.52 /{ }^{\circ}$ \\
OM distance & $0.15 / \AA$ \\
Lennard-Jones epsilon for $\boldsymbol{O}-\boldsymbol{O}\left(\varepsilon_{O O}\right)$ & $0.1550 / \mathrm{kcal} \mathrm{mol}^{-1}$ \\
Lennard-Jones sigma for $\boldsymbol{O - O}\left(\sigma_{O O}\right)$ & $3.1536 / \AA$ \\
Lennard-Jones epsilon for $\mathrm{HH}\left(\varepsilon_{H H}\right), \boldsymbol{O H}\left(\varepsilon_{O H}\right)$ & $0 / \mathrm{kcal} \mathrm{mol}^{-1}$ \\
Lennard-Jones sigma for $\boldsymbol{H H}\left(\sigma_{H H}\right), \boldsymbol{O H}\left(\sigma_{O H}\right)$ & $0 / \AA$ \\
Coulombic cutoff & $8.5 / \AA$ \\
\hline
\end{tabular}

Table 2. Energy parameter $(\epsilon)$ and Length scale of Carbon $(\sigma)$

\begin{tabular}{lcc}
\hline & $\boldsymbol{\epsilon}($ Kcal/mole $)$ & $\boldsymbol{\sigma}(\AA)$ \\
\hline Carbon & 0.06077 & 3.369 \\
\hline
\end{tabular}


The interaction parameters of water-nanotube are derived by Lorentz and Berthelot mixing law, $\epsilon_{i j}=\sqrt{\epsilon_{i} \epsilon_{j}}, \sigma_{i j}=\frac{\sigma_{i}+\sigma_{j}}{2}$; in which $i$ and $j$ show the kind of particle. As mentioned previously, TIP4P water model were used for all simulations, so its energy parameters and length scales are $\epsilon_{O-O}=0.1550 \mathrm{Kcal} / \mathrm{mole}, \sigma_{O-O}=3.1536 \AA, \epsilon_{H-H}=\epsilon_{H-O}=\sigma_{H-H}=\sigma_{H-O}=0$ [24][25]

A canonical (NVT) ensemble is applied to retain the number of all particles $N$, system volume $V$ and system temperature $T$ as constant values in the simulation process. All the information that are used as simulation inputs, are tabulated in Table 3.

Table 3. Input information for different simulations

\begin{tabular}{cccc}
$\begin{array}{c}\text { Percent of volume } \\
\text { fraction }(\phi \%)\end{array}$ & \multicolumn{2}{c}{$\begin{array}{c}\text { Number of all } \\
\text { particles }(\boldsymbol{N})\end{array}$} & System volume $(\boldsymbol{V})$ \\
\cline { 2 - 4 } & $\begin{array}{c}\text { Water } \\
(\mathbf{H}+\mathbf{O})\end{array}$ & $\begin{array}{c}\text { CNT } \\
(\mathbf{C})\end{array}$ & $\boldsymbol{L}_{\boldsymbol{x}} \times \boldsymbol{L}_{\boldsymbol{y}} \times \boldsymbol{L}_{z}\left(\mathbf{\mathbf { A }}^{\mathbf{3}}\right)$ \\
\hline $\mathbf{0 . 5 5 7}$ & 20118 & 312 & $59.6 \times 59.6 \times 59.6$ \\
$\mathbf{1}$ & 11100 & 312 & $49.0 \times 49.0 \times 49.0$ \\
$\mathbf{2}$ & 5472 & 312 & $36.6 \times 36.6 \times 44.0$ \\
$\mathbf{3}$ & 3612 & 312 & $30.0 \times 30.0 \times 44.0$ \\
\hline
\end{tabular}

The purpose of this article is to compute nanofluid's viscosity with LAMMPS software, which is an open-source MD package[13]. The nanofluid whose viscosity is to be assessed, is regarded as a dispersion of carbon nanotube in pure water with special volume fraction at room temperature. To achieve this goal, the Green-Kubo's approach is used. Green-Kubo is an EMD method; the trend of this theory is written below[19][26]:

$\eta=\frac{V}{3 k_{B} T} \int_{0}^{\tau}\left\langle J_{x y}(t) J_{x y}\left(t+t_{1}\right)+J_{y z}(t) J_{y z}\left(t+t_{1}\right)+J_{z x}(t) J_{z x}\left(t+t_{1}\right)\right\rangle d t_{1}$

where the $x y$ component of the stress tensor has the following form for a binary mixture:

$J_{x y}=\frac{1}{V}\left[\sum_{\alpha=1}^{2} \sum_{i=1}^{N_{\alpha}} m_{\alpha} \dot{x}_{i} \dot{y}_{i}+\frac{1}{2} \sum_{\alpha=1, i \neq j}^{N_{1}} F_{x, i j} y_{i j}+\frac{1}{2} \sum_{\alpha=2, i \neq j}^{N_{2}} F_{x, i j} y_{i j}+\sum_{i=1}^{N_{1}} \sum_{j=1}^{N_{2}} F_{x, i j} y_{i j}\right]$

where subscript $\alpha=1$ refers to molecules, subscript $\alpha=2$ refers to nanoparticles, $m_{i}$ is the mass of a particle, $V$ is the volume of the system, $T$ is the temperature of the medium, $\tau$ is the time to reach a plateau value, $F$ is the force acting on a molecule or nanoparticle, $x$ and $y$ are the coordinates of the molecule or nanoparticle, and $N_{1}$ and $N_{2}$ are the numbers of molecules and nanoparticles, respectively. The angular brackets[19] in Eq. (3) and Eq. (4) mean an ensemble average. These equations were derived[26] for molecular systems; however, some authors [27] believe that they have the same format for dispersed systems, in particular for nanofluids [28].

\section{Results and Discussions}


In the present study, the influence of change in volume fraction is investigated by changing the number of water molecules. As a result, the simulation box size will differ; the size and type of nanotube are constant in all simulations. The percentage of altered volume fractions is $\phi=0.557,1,2,3 \%$. A typical nanofluid is created with an SWCNT $(6,6)$ added among the water molecules in a confined volume. Simulations have been done at two temperatures, $298 \mathrm{~K}$, and $313 \mathrm{~K}$ with different volume fractions. The system is equilibrated in the canonical ensemble for 16 ps, that will be showed to be more enough for this system.

\subsection{Thermodynamic Equilibration}

The equilibration of nanofluid should be achieved to guarantee that the system is in a stable state. Therefore, the equilibrium of the system has been monitored by quantities such as the kinetic energy, the potential energy, the total energy, the temperature and the pressure of the system. At this point, the system is stabilized for $16 \mathrm{ps}$. The main intention is to keep the system at the desired temperature. Thus, the temperature is controlled regularly, and if it comes to be out of the certain tolerance of the desired temperature, the velocities are rescaled in order to make the temperature go back near the target temperature [1]. To calculate the stability of the system it is essential to measure the fluctuation of the total energy. The estimated values should conserve at a certain amount of system's total energy and, the oscillations should be small enough. Figures 3 and 4 indicate the kinetic energy, the potential energy, and the total energy of water-SWCNT nanofluid for different volume fractions at $T=298 K$ and $T=313 K$. It is apparent that the total energy is based on the summation of potential and kinetic energies. However, the potential energy is the dominant portion of total energy. The kinetic energy is due to the movement of particles that is not comparable with the massive interatomic forces resulting in the high potential energy. It is clear that nanofluids' total energy at whole volume fractions will be converged smoothly to the constant energy within 16ps of the equilibration phase. Also, it exhibits that the simulated systems at $\phi=3 \%$ have the lowest kinetic, but potential and total energy are the highest in comparison to others. As it is apparent in figures 3 and 4, the kinetic energy decreased by increasing volume fraction; this depends on the molecular mass of the system. If the molecular mass is calculated for each volume fraction, it will be revealed that the average molecular mass decreases by the increase in the volume fraction. The average temperature will be set to the desired temperature $(298 \mathrm{~K}$ or $313 \mathrm{~K})$ by Nose-Hoover thermostat, although the system temperature is oscillating. It means that the velocity that is related to temperature is almost the same for all volume fractions and the only parameter that makes changes in the 
kinetic energy is average molecular mass. For calculating average mass fraction, Eq. (5) is used and the results are tabulated in Table 4.

$M_{\text {ave }}=\frac{M_{\mathrm{H}_{2} \mathrm{O}} \times N_{\mathrm{H}_{2} \mathrm{O}}+M_{\mathrm{C}} \times N_{C}}{N_{\mathrm{H}_{2} \mathrm{O}}+N_{C}}$

Table 4. Average molecular mass for different volume fractions

\begin{tabular}{lcccc}
\hline$\phi(\%)$ & $\mathbf{0 . 5 5 7}$ & $\mathbf{1}$ & $\mathbf{2}$ & $\mathbf{3}$ \\
\hline$M_{\text {ave }}$ & 17.9237 & 17.8512 & 17.6915 & 17.5380 \\
\hline
\end{tabular}

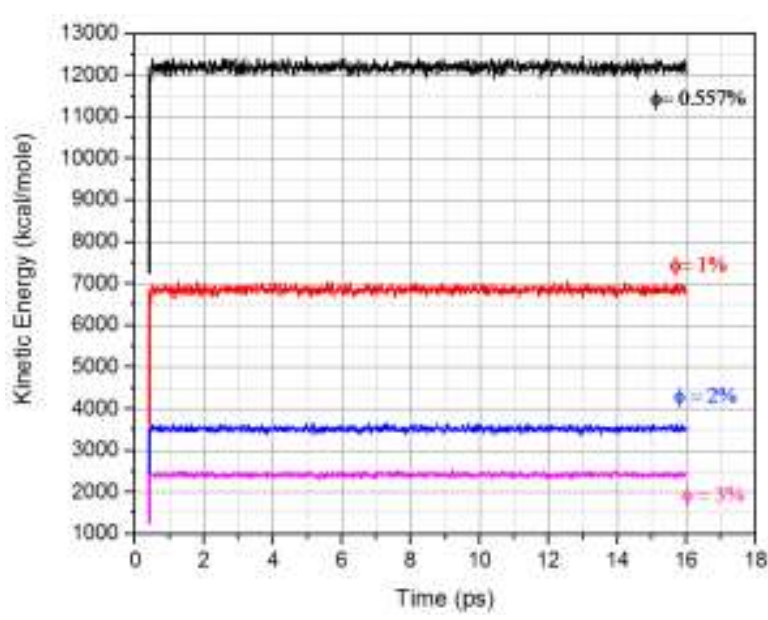

(a)

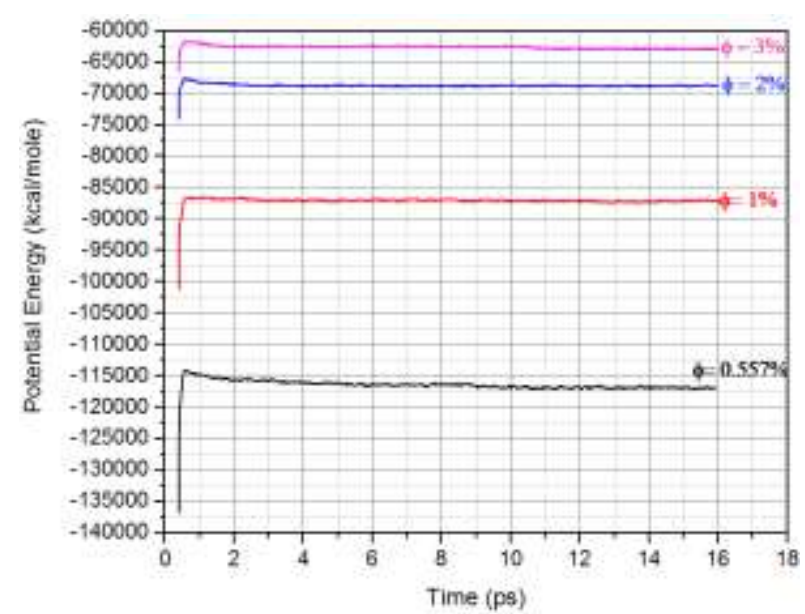

(b)

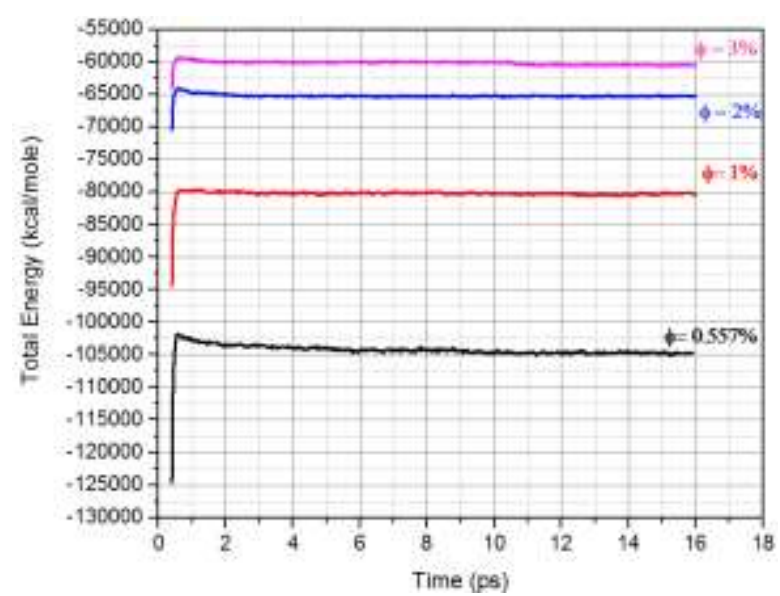

(c)

Figure 3. Time evolution of energy for $T=298 K$ at equilibrium process for water-SWCNT nanofluid at different volume fractions (a) Kinetic energy (b) Potential energy (c) Total energy. 


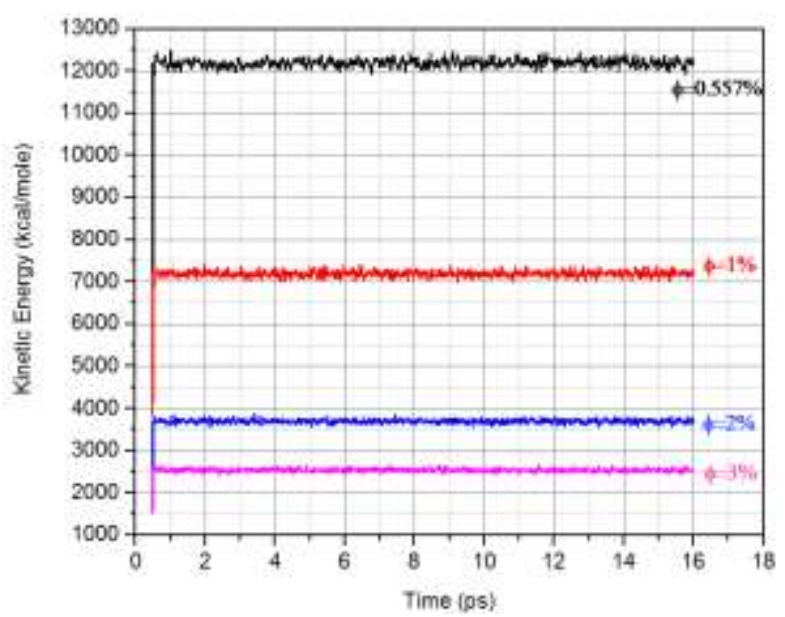

(a)

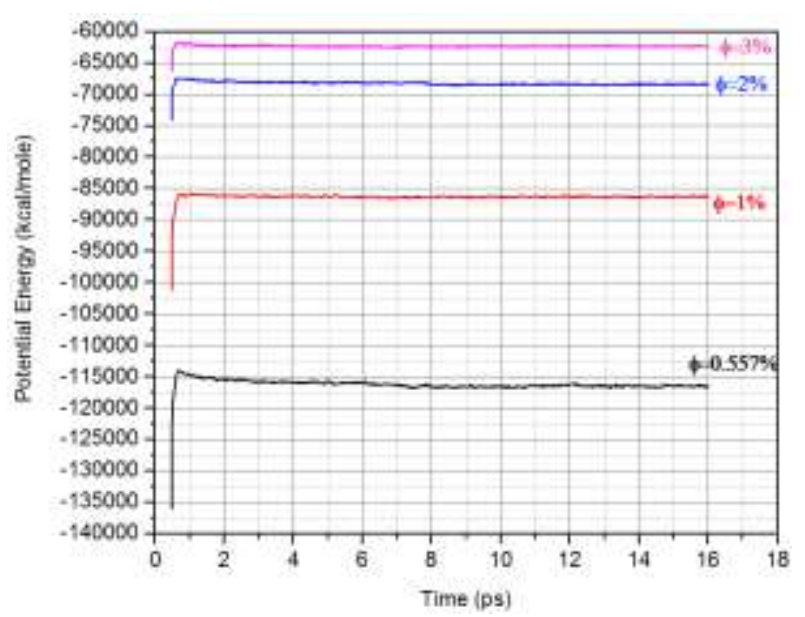

(b)

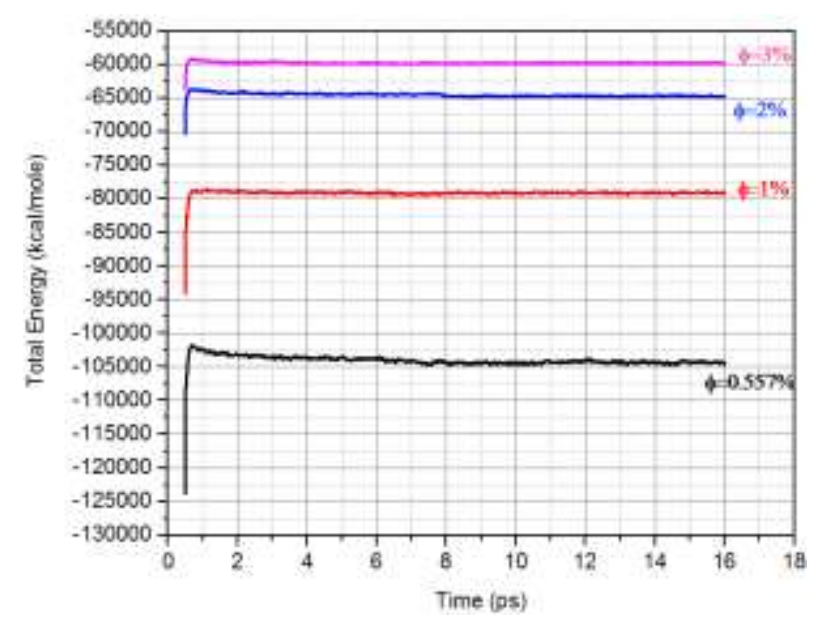

(c)

Figure 4. Time evolution of energy for $T=313 K$ at equilibrium process for water-SWCNT nanofluid at different volume fractions (a) Kinetic energy (b) Potential energy (c) Total energy.

Figures 5 and 6 presented the temperature and enthalpy fluctuation curve of nanofluid at different volume fractions versus time. Enthalpy is shown at equilibrium process; also temperatures are displayed in viscosity calculation's process. Achieving to the equilibrium state in the system is happened by NVT ensemble. Also, the enthalpy of nanofluid converges at within 16ps, which signifies the stable conditions for production of thermodynamic and physical properties. 


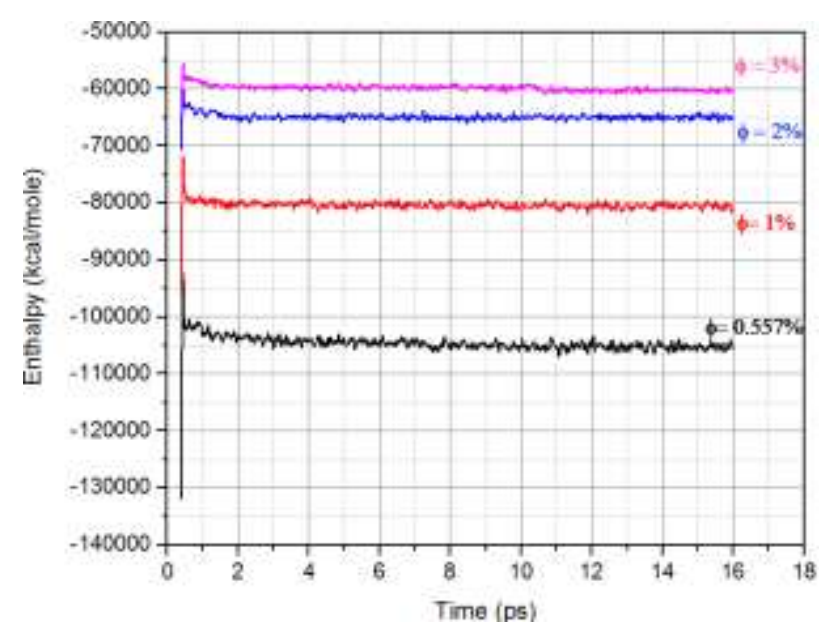

(a)
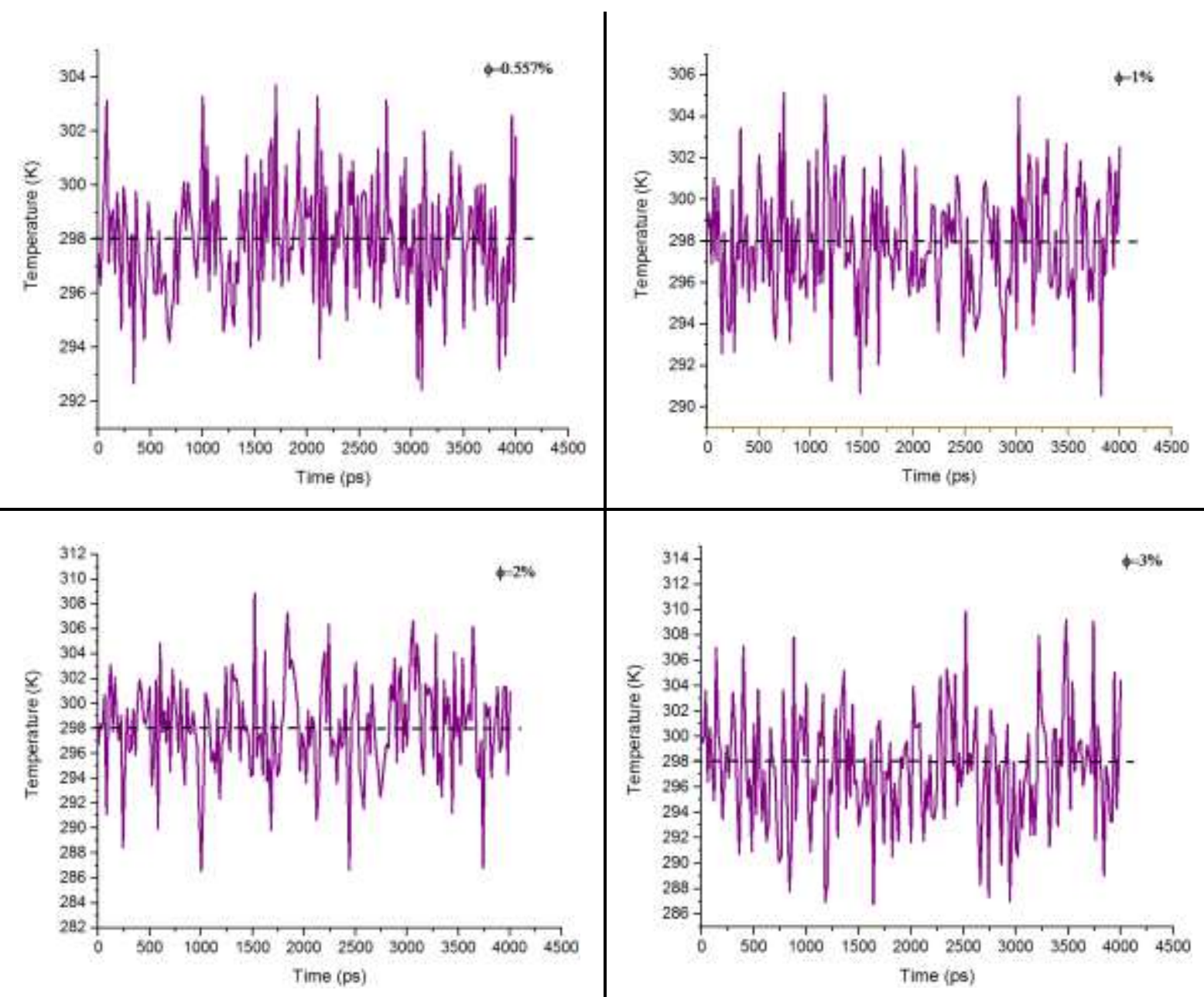

(b)

Figure 5. (a) Enthalpy in equilibrium process, and (b) Temperature oscillations in viscosity calculation process for water-SWCNT nanofluid at different volume fraction and $T=298 K$. 


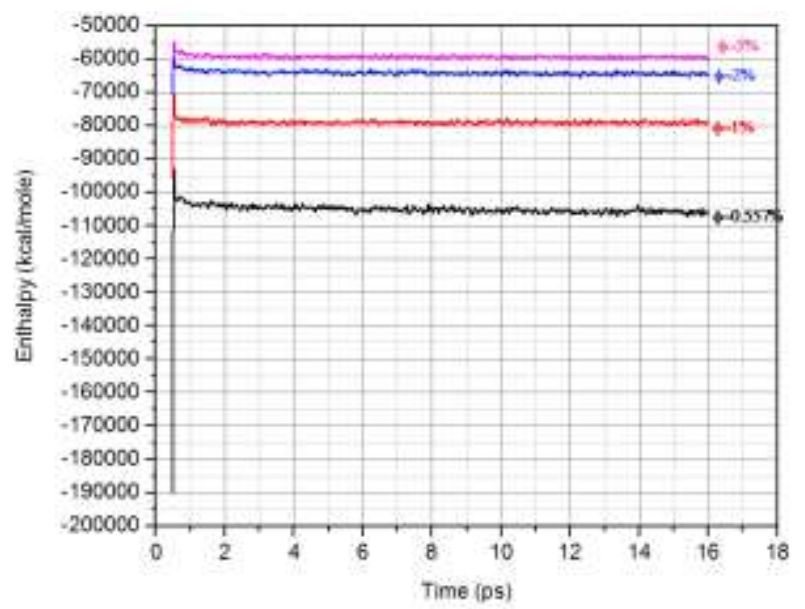

(a)
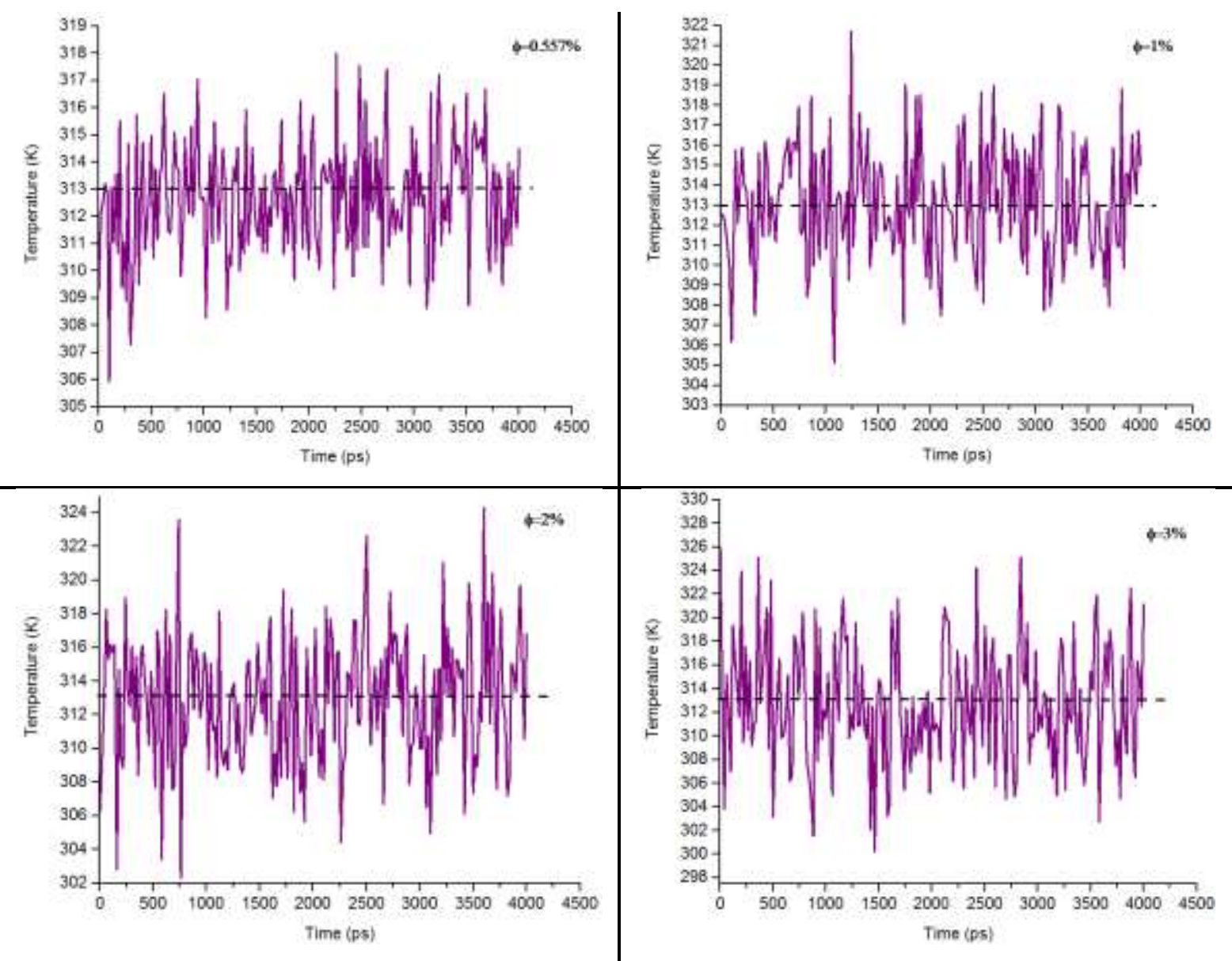

(b)

Figure 6. (a) Enthalpy at equilibrium process, and (b) Temperature oscillations in viscosity calculation process for water-SWCNT nanofluid at different volume fractions and $T=313 \mathrm{~K}$.

\subsection{Viscosity calculation}

In this section, the amount of viscosity calculated by MDS and is compared with theoretical models. Several theoretical formulations have been developed to correlate the relative 
viscosity of nanofluids to particle volume fraction. The relative viscosity $\left(\mu_{r}\right)$ is described by the ratio of nanofluid' viscosity, $\mu_{n f}$, to base fluid's viscosity, $\mu_{b f}$ :

$\mu_{r}=\frac{\mu_{n f}}{\mu_{b f}}$

These formulations are drawn from Einstein's initiate model[29], which is based on the idea of viscous fluid including non-interacting hard spheres with particle volume fraction of less than $1 \%$ :

$\mu_{r}=(1+2.5 \phi)$

where $\mu_{r}$ is the relative viscosity as defined above, and $\phi$ is the volume fraction of nanoparticle in the base fluid.

Later, Brinkman[30] developed Einstein's equation to suspensions with medium particle volume fraction, usually less than $4 \%$ :

$\mu_{r}=\frac{1}{(1-\phi)^{2.5}}$

Considering the Brownian motion of nanoparticles and the interaction between a pair of particles, Batchelor[31] proposed the following equation.

In Eq. (9), $\eta$ is the intrinsic viscosity, and $\mathrm{k}_{\mathrm{H}}$ is the Huggins' coefficient. The values of $\eta$ and $\mathrm{k}_{\mathrm{H}}$ are 2.5 and 6.5 , respectively, for spherical particles.

$\mu_{r}=\left(1+\eta \phi+k_{H} \phi^{2}+\ldots\right)$

Maron and Pierce derived another equation that applied in this article from consideration of the Ree-Eyring flow equations[32], [33]. Equation (10) was obtained from a minimum principle applied to the energy dissipated by viscous effects.

$\mu_{r}=\left(1-\frac{\phi}{\phi_{m}}\right)^{-2}$

The $\phi_{m}$ is the maximum particle volume fraction when the viscosity is infinite. The viscosity's certainty is measured by plotting the arithmetic averages $\left(v_{a v e}=\frac{v_{x x}+v_{y y}+v_{z z}}{3}\right)$ during the time evolution of the system. Figure 7 shows the values of average viscosity for different volume fractions and temperatures. The time evolution has continued until the average viscosity converged to a certain amount. Besides, it is obvious that the average viscosity increases by an increment in the volume fraction. Through increasing in the volume fraction, the fluid will be demanded more energy to motion; hence the viscosity of the liquid will be increased. 


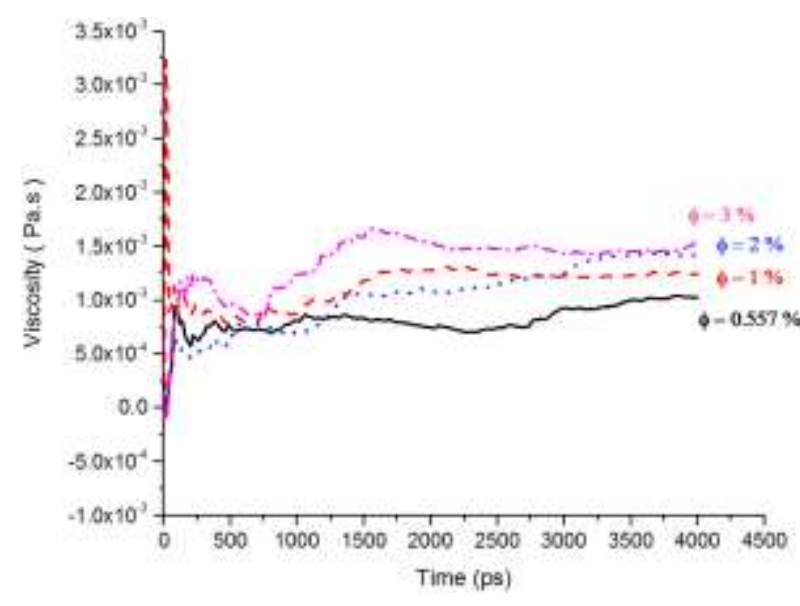

(a)

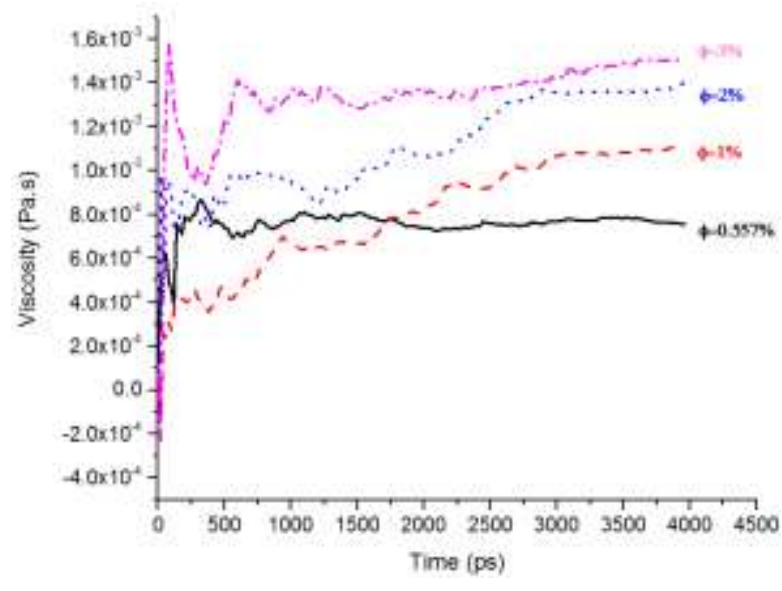

(b)

Figure 7. Time evolution of nanofluid's viscosity for different volume fractions: a) $T=298 K$ and, b)

$$
T=313 K \text {. }
$$

Figures 8 and 9 indicate the values of $v_{x x}, v_{y y}, v_{z z}$ and average viscosity at $T=298 K$ and $T=313 K$ for $\phi=0.557 \%, \phi=1 \%, \phi=2 \%$ and, $\phi=3 \%$, respectively. The time evolution has continued until the average viscosity converged to a certain amount. It is apparent that the amount of average viscosity increases on the increase in the volume fraction; and also, it is decreased while the temperature is increased. Because of the increment in volume fraction, liquid's (water) amount has reduced in compared to solid's (CNT); and so the fluidity of system has decreased; as a result of this phenomenon, the fluid has needed more energy to motion. It means viscosity has increased by the escalation in volume fraction.
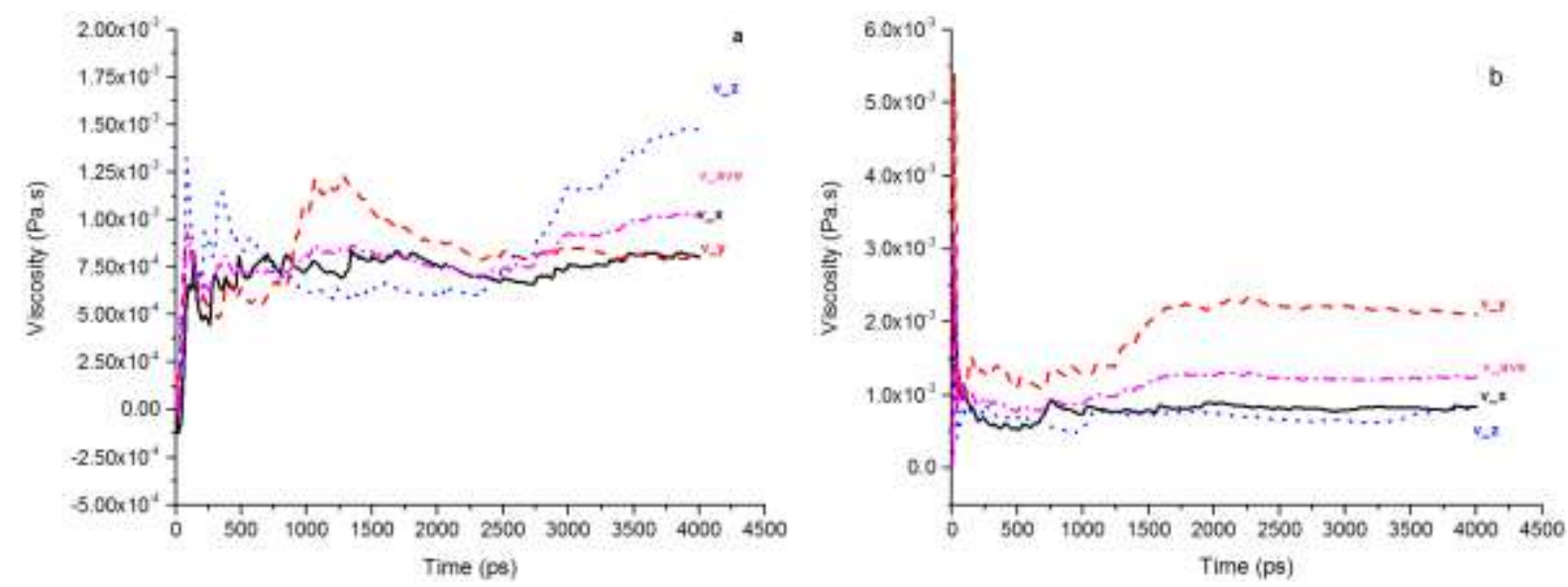

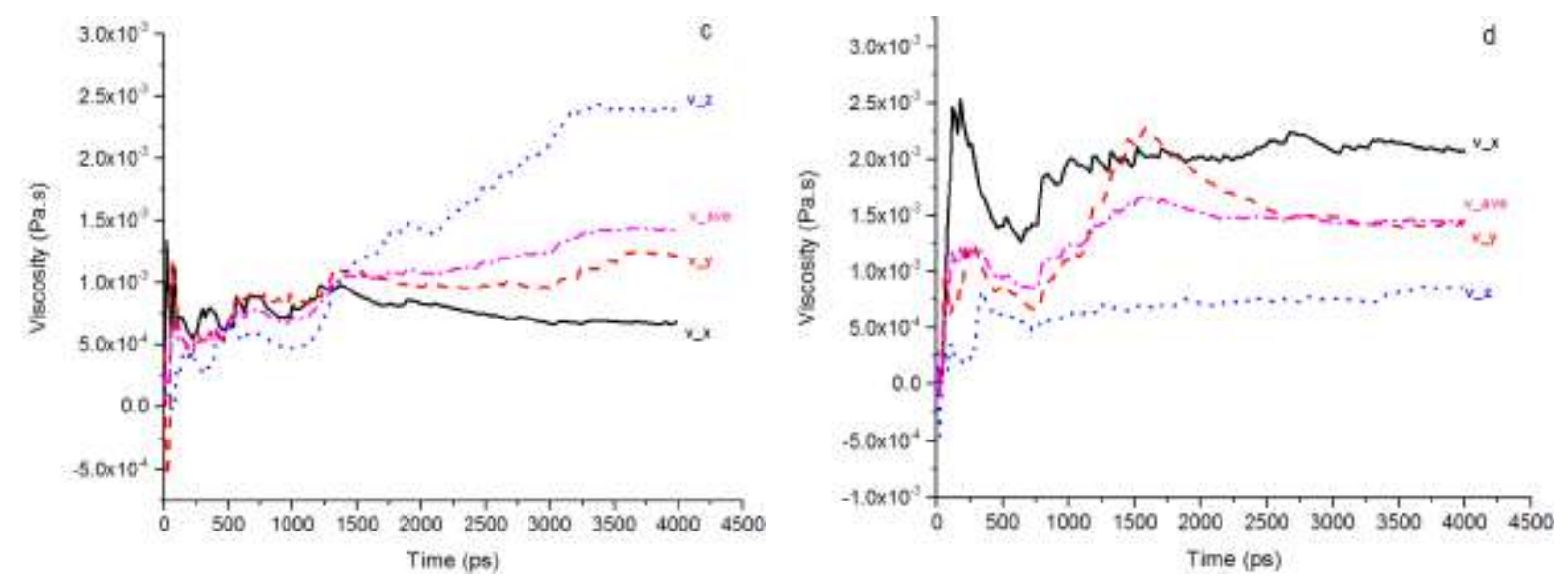

Figure 8. Time evolution of nanofluid viscosity for $v_{x x}, v_{y y}, v_{z z}$ and $v_{a v e}$ at $T=298 K$ : (a) $\phi=0.557 \%$ (b)

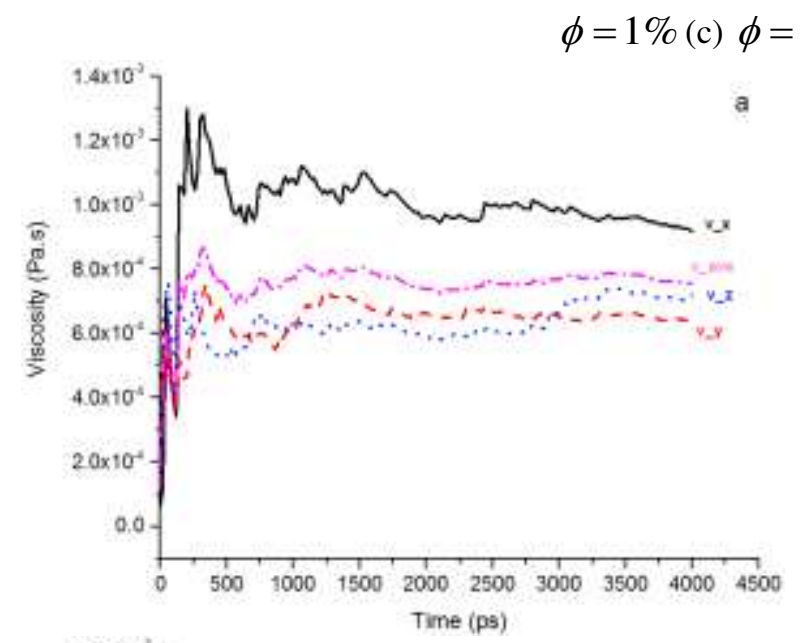
$\%$ (d) $\phi=3 \%$.
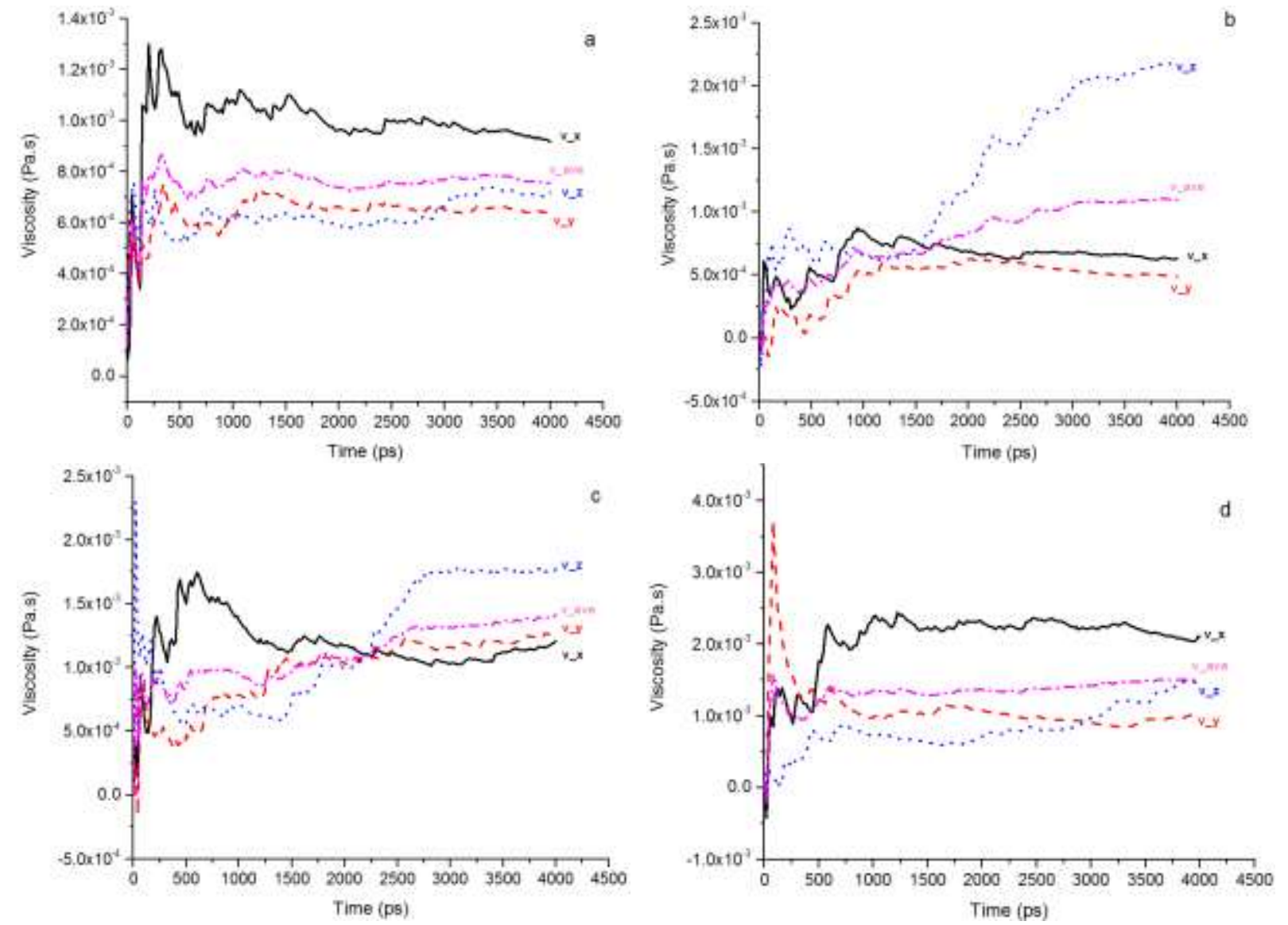

Figure 9. Time evolution of nanofluid viscosity for $v_{x x}, v_{y y}, v_{z z}$ and $v_{a v e}$ at $T=313 K$ : (a) $\phi=0.557 \%$ (b)

$$
\phi=1 \% \text { (c) } \phi=2 \% \text { (d) } \phi=3 \% \text {. }
$$

Figures 10 and 11 indicate the result of MD calculation and the comparison with two theoretical equation, Batchelor and Maron-Pierce equations. It is clear that MD would be able to estimate the trend of viscosity in different temperatures and volume fractions. The MD can be chosen as an acceptable method to calculate the viscosity of nanofluid's where there is no experimental answer. 


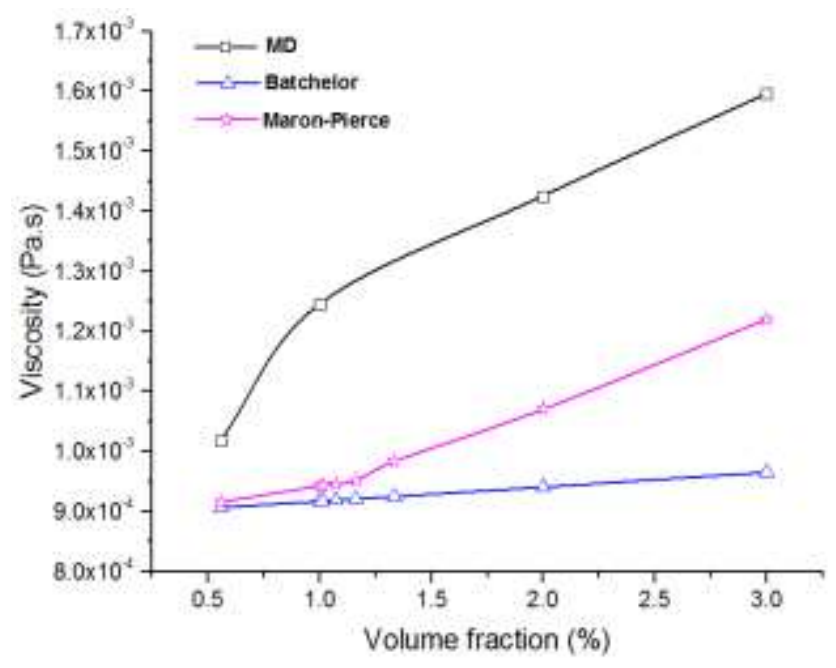

Figure 10. Calculation and comparison of Water-CNT nanofluid's viscosity against volume fraction (\%) at $T=298 K$.

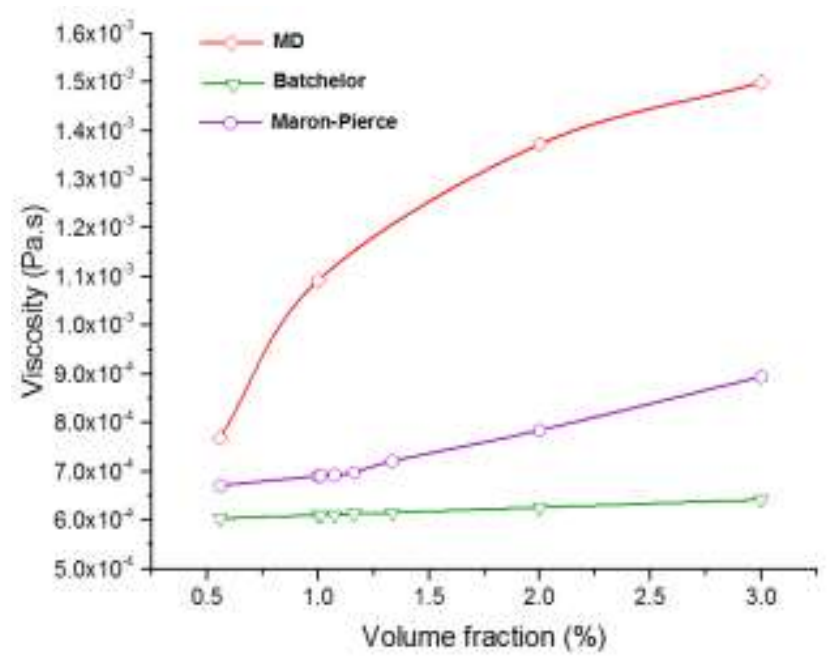

Figure 11. Calculation and comparison of Water-CNT nanofluid's viscosity against volume fraction (\%) at $T=313 K$.

In order to focus more on the results, the exact amounts of viscosities at both temperatures (298K and 313K) has tabulated in table 5. Generally, viscosity and volume fraction have a direct relationship but temperature do not. MD correctly estimates the ascending behavior of viscosity by the increment in the volume fraction and temperature differences.

Table 5. Comparison of viscosity of water-CNT nanofluid with theoretical modeling in different volume fractions: a) $298 \mathrm{~K}$, and, b) $313 \mathrm{~K}$.

(a)

\begin{tabular}{cccc}
\hline $\begin{array}{c}\text { Volume fraction } \\
(\%)\end{array}$ & Batchelor Eq. [31] & $\begin{array}{c}\text { Maron-Pierce Eq. } \\
{[32],[33]}\end{array}$ & MD, present study \\
\hline $\mathbf{0 . 5 5 7}$ & $9.065 \mathrm{E}-4$ & $9.155 \mathrm{E}-4$ & $1.019 \mathrm{E}-3$ \\
$\boldsymbol{1}$ & $9.167 \mathrm{E}-4$ & $9.424 \mathrm{E}-4$ & $1.245 \mathrm{E}-3$ \\
$\boldsymbol{2}$ & $9.403 \mathrm{E}-4$ & $1.071 \mathrm{E}-3$ & $1.426 \mathrm{E}-3$ \\
\hline
\end{tabular}




\begin{tabular}{cccc}
\hline $\mathbf{3}$ & $9.647 \mathrm{E}-4$ & $1.220 \mathrm{E}-3$ & $1.598 \mathrm{E}-3$ \\
\hline & & (b) & \\
\hline $\begin{array}{c}\text { Volume fraction } \\
(\%)\end{array}$ & Batchelor Eq. [31] & Maron-Pierce Eq. & MD, present study \\
{$[32],[33]$} & \\
\hline $\mathbf{0 . 5 5 7}$ & & $6.7140 \mathrm{E}-4$ & $7.6915 \mathrm{E}-4$ \\
$\boldsymbol{I}$ & $6.0380 \mathrm{E}-4$ & $6.9116 \mathrm{E}-4$ & $1.0926 \mathrm{E}-3$ \\
$\mathbf{2}$ & $6.1057 \mathrm{E}-4$ & $7.8471 \mathrm{E}-4$ & $1.3718 \mathrm{E}-3$ \\
$\mathbf{3}$ & $6.2627 \mathrm{E}-4$ & $8.9471 \mathrm{E}-4$ & $1.4988 \mathrm{E}-3$ \\
\hline
\end{tabular}

\subsection{Correlation}

According to the obtained results from MD, a theoretical formula for calculating SWCNTwater viscosity is offered by the authors for $\phi \leq 3 \%$.

$$
\mu=A(\operatorname{Ln} T)^{n}+B \zeta
$$

where $\mu$ is nanofluid's viscosity, $T$ is temperature and $\zeta$ is percent of volume fraction ( $\zeta=\phi \times 100) . A=5.7 \times 10^{25}, B=3 \times 10^{-4}, n=-38.1$ are constant values.

Unfortunately, there aren't enough experimental data for SWCNT-water nanofluid; therefore, correlation is compared with MWCNT-water nanofluid data [3]; so the error is not irrefutable. Figure 12 shows the experimental data and correlation predictions at low volume fractions. As it has illustrated, the correlation shows acceptable agreement with experiment.

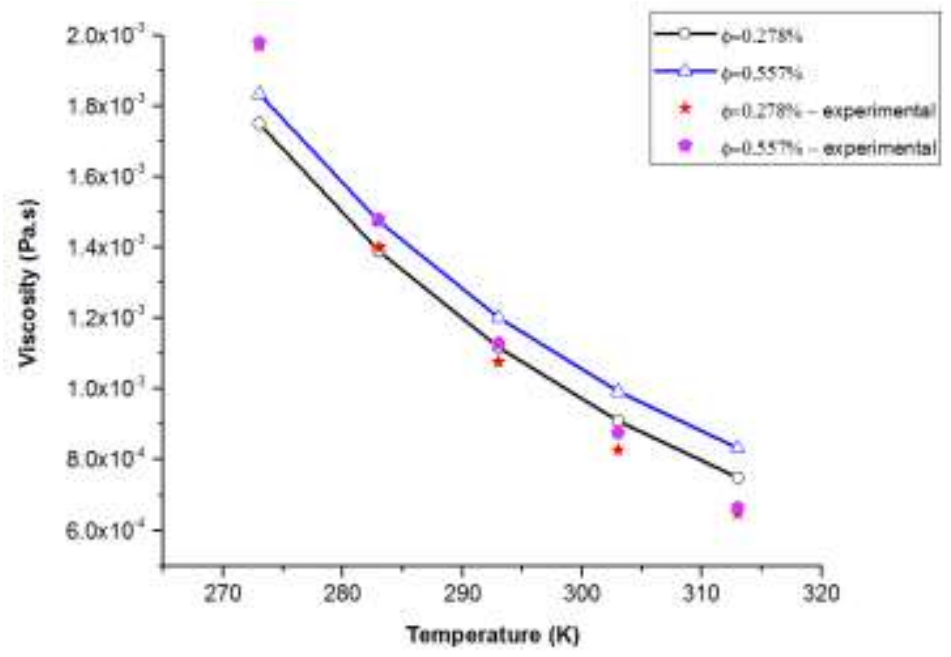

Figure 12. Comparison of experimental and correlation prediction for low volume fraction at different temperatures.

Figure 13 shows the capability of the correlation equation in the prediction volume fraction and also, the temperature's influence on the viscosity variation. It has revealed that viscosity 
decreased by increasing temperature, plus increased by volume fraction increment; both of them have predicted by the correlation. Also, the results of pure water [34] have shown in this figure, which presented that the correlation predicted a higher amount than pure water, which is entirely reasonable.

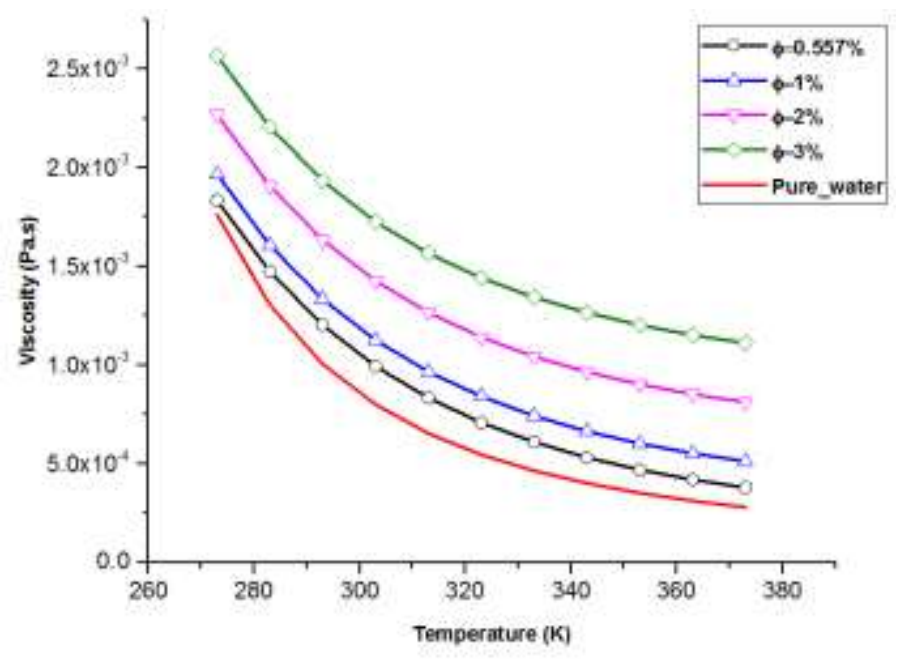

Figure 13. The capability of correlation in predicting volume fraction and temperature influence on the viscosity.

Figures 14 and 15 aim to clarify how the correlation predicted MD results for different volume fractions. According to figures, this correlation is acceptable for estimating viscosity since it can determine the impacts of volume fraction and temperature on it.

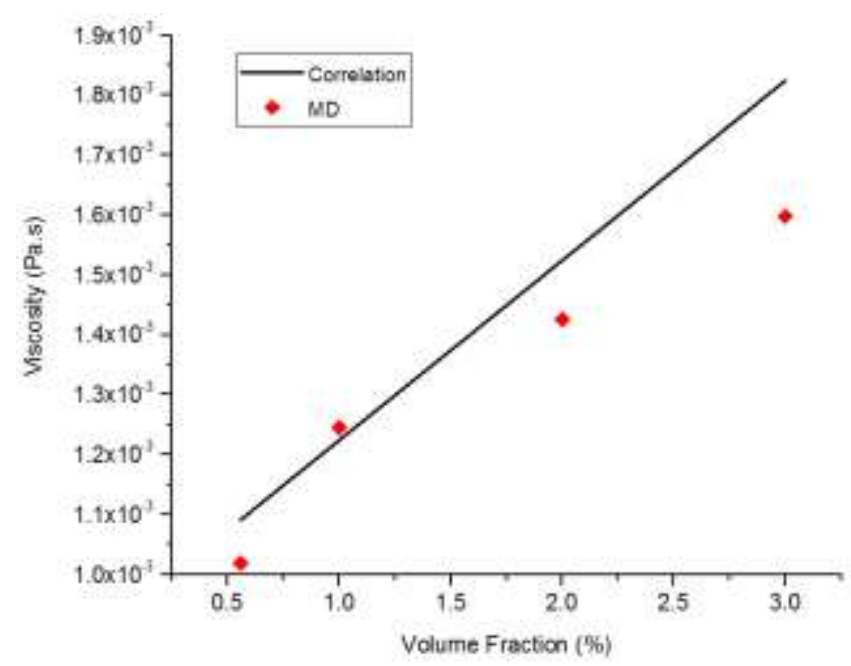

Figure 14. Comparison of MD results and correlation prediction for viscosity versus volume fraction at $\mathrm{T}=298 \mathrm{~K}$. 


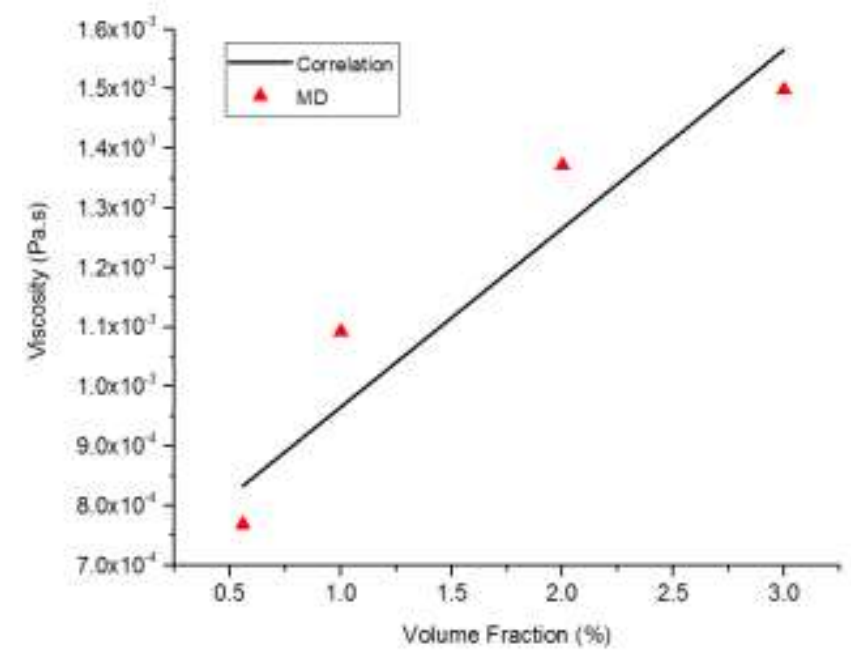

Figure 15. Comparison of MD results and correlation prediction for viscosity versus volume fraction at $\mathrm{T}=313 \mathrm{~K}$.

\section{Conclusion}

We have carried out a research study on the impact of volume fraction on the viscosity of a typical water-SWCNT nanofluid at two different temperatures (298K and $313 \mathrm{~K}$ ) by molecular dynamics simulation. It has found that the volume fraction plays a critical role in the viscosity of nanofluids including CNT as nanoparticles. Also, the values of average arithmetic viscosity vectors in different volume fractions are derived. Moreover, the magnitude of viscosity is increased by the volume fraction increment. The accuracy of the MDS result is determined by comparing with the two theoretical equations, Batchelor and Maron-Pierce, which the validity of their results have already been proven by lots of experimental data. It is revealed that increasing volume fraction as a result of increasing the effective volume fraction will increase viscosity. MD is able to estimate viscosity in acceptable range so it can be applied when there is no experimental data or it is difficult to do experimental research. In the end, the authors offered a theoretical correlation that obtained from results. In the aforementioned formula, volume fraction, temperature and viscosity linked to each other. It showed a good agreement with theoretical and experimental data in the allowable range of volume fractions.

\section{Acknowledgements}

We gratefully acknowledge the support of the RCGI, Research Centre for Gas Innovation, hosted by the University of São Paulo (USP) and sponsored by FAPESP, São Paulo Research Foundation (2014/50279-4) and Shell Brasil. Also, the second author would like to acknowledge the support of FAPESP (2018/16803-9). 


\section{Compliance with ethical standards}

Conflict of Interest: On behalf of all authors, the corresponding author states that there is no conflict of interest.

Ethics approval: This work follows all the ethics for publication.

Consent to participate: The work is carried out with the consent from responsible authorities.

Consent for publication: No objections are there from any author or affiliated institution.

\section{REFRENCES:}

1.

3.

4.

5.

6.

7.

8.

9.

10.

Razmara, N., Namarvari, H., \& Romano, J. (2019). A new correlation for viscosity of model watercarbon nanotube nano fl uids: Molecular dynamics simulation. Journal of Molecular Liquids, 293, 111438. https://doi.org/10.1016/j.molliq.2019.111438

Leong, K. Y., Fadhillahanafi, N. M., \& Chew, S. P. (2006). VISCOSITY CHARACTERISTIC OF CARBON NANOTUBE BASED NANOFLUIDS AT ROOM TEMPERATURE. 11(10), 65846588.

Halelfadl, S., Estellé, P., Aladag, B., Doner, N., \& Maré, T. (2013). Viscosity of carbon nanotubes water-based nanofluids: Influence of concentration and temperature. International Journal of Thermal Sciences, 71, 111-117. https://doi.org/10.1016/j.ijthermalsci.2013.04.013

Esfe, M. H., Esfandeh, S., \& Rejvani, M. (2018). Modeling of thermal conductivity of MWCNT-SiO 2 (30: 70\%)/EG hybrid nanofluid, sensitivity analyzing and cost performance for industrial applications. Journal of Thermal Analysis and Calorimetry, 131(2), 1437-1447.

Esfe, M. H., Rejvani, M., Karimpour, R., \& Arani, A. A. A. (2017). Estimation of thermal conductivity of ethylene glycol-based nanofluid with hybrid suspensions of SWCNT-Al 2 O 3 nanoparticles by correlation and ANN methods using experimental data. Journal of Thermal Analysis and Calorimetry, 128(3), 1359-1371.

Kuang, Y. D., Shi, S. Q., Chan, P. K. L., \& Chen, C. Y. (2010). Self-assembly of carbon nanotubes and boron nitride nanotubes into coaxial structures. Computational Materials Science, 50(2), 645-650. https://doi.org/10.1016/j.commatsci.2010.09.029

Golberg, D., Bando, Y., Huang, Y., Terao, T., Mitome, M., \& Tang, C. (2010). Boron Nitride Nanotubes and. 4(6), 2979-2993.

Zhang, H., Ye, H., Zheng, Y., \& Zhang, Z. (2011). Prediction of the viscosity of water confined in carbon nanotubes. Microfluidics and Nanofluidics, 10(2), 403-414. https://doi.org/10.1007/s10404-010-0678-0

Vakili-Nezhaad, G., \& Dorany, A. (2012). Effect of single-walled carbon nanotube on the viscosity of lubricants. Energy Procedia, 14(1998), 512-517. https://doi.org/10.1016/j.egypro.2011.12.967

Murshed, S. M. S., Leong, K. C., \& Yang, C. (2008). Investigations of thermal conductivity and viscosity of nanofluids. International Journal of Thermal Sciences, 47(5), 560-568. https://doi.org/10.1016/j.ijthermalsci.2007.05.004 
11.

12.

13.

14.

15.

16.

17.

18.

19.

20.

21.

22.

23.

24.

25.

26.

Lu, G., Wang, Y. D. X., Duan, Y.-Y., \& Wang, X.-D. (2014). Surface tension, viscosity, and rheology of water-based nanofluids: a microscopic interpretation on the molecular level. Journal of Nanoparticle Research, 16(9), 2564. https://doi.org/10.1007/s11051-014-2564-2

Ravisankar, B., Chand, V. T., Journal, I., Engineering, M., \& Doi, P. (2013). Influence of nanoparticle volume fraction, particle size and temperature on thermal conductivity and viscosity of nanofluids-A review. International Journal of Automotive and Mechanical Engineering, 8(December), 1316.

Plimpton, S. (1995). Fast Parallel Algorithms for Short - Range Molecular Dynamics. Journal of Computational Physics, 117(June 1994), 1-19. https://doi.org/10.1006/jcph.1995.1039

Ge, S., Zhang, X.-X., \& Chen, M. (2011). Viscosity of $\mathrm{NaCl}$ aqueous solution under supercritical conditions: a molecular dynamics simulation. Journal of Chemical \& Engineering Data, 56(4), $1299-1304$.

GUO, G.-J., \& ZHANG, Y.-G. (2001). Equilibrium molecular dynamics calculation of the bulk viscosity of liquid water. Molecular Physics, 99(4), 283-289. https://doi.org/10.1080/00268970010011762

Chen, T., Smit, B., \& Bell, A. T. (2009). Are pressure fluctuation-based equilibrium methods really worse than nonequilibrium methods for calculating viscosities? Journal of Chemical Physics, 131(24), 1-2. https://doi.org/10.1063/1.3274802

Lou, Z., \& Yang, M. (2015). Molecular dynamics simulations on the shear viscosity of Al 2 O 3 nanofluids. Computers \& Fluids, 117, 17-23.

Sarkar, S., \& Selvam, R. P. (2007). Molecular dynamics simulation of effective thermal conductivity and study of enhanced thermal transport mechanism in nanofluids. Journal of Applied Physics, 102(7). https://doi.org/10.1063/1.2785009

Rudyak, V. Y., \& Krasnolutskii, S. L. (2014). Dependence of the viscosity of nanofluids on nanoparticle size and material. Physics Letters A, 378(26), 1845-1849.

Teng, K., Hsiao, P., Hung, S., Chieng, C., Liu, M., \& Lu, M. (2007). Enhanced Thermal Conductivity of Nanofluids Diagnosis by Molecular Dynamics Simulations. 8(4). https://doi.org/10.1166/jnn.2007.007

Humphrey, W., Dalke, A., \& Schulten, K. (1996). VMD: Visual molecular dynamics. In Journal of Molecular Graphics (Vol. 14, Issue 1, pp. 33-38). https://doi.org/10.1016/02637855(96)00018-5

Javanmardi, M. J., \& Jafarpur, K. (2013). A Molecular Dynamics Simulation for Thermal Conductivity Evaluation of Carbon Nanotube-Water Nanofluids. Journal of Heat Transfer, 135(4), 42401. https://doi.org/10.1115/1.4022997

Jabbari, F., Rajabpour, A., \& Saedodin, S. (2018). Viscosity of carbon nanotube / water nanofluid. Journal of Thermal Analysis and Calorimetry, 6. https://doi.org/10.1007/s10973-018-7458-6

Sardroodi, J. J., Azamat, J., Rastkar, A., \& Yousefnia, N. R. (2012). The preferential permeation of ions across carbon and boron nitride nanotubes. Chemical Physics, 403, 105-112. https://doi.org/10.1016/j.chemphys.2012.05.017

Binders, B. L. R. (2003). LAMMPS Users Manual 19 May 2017 version http://lammps.sandia.gov Sandia Narional Laboratories Copyright (2003) Sandia Corporation. This software and manual is distributed under the GNU General Public License. WD Info, 2015, 2004. https://doi.org/10.1002/ejoc.201200111

Cheung, D. L., Anton, L., Allen, M. P., \& Masters, A. J. (2008). Computer simulation of liquids and liquid crystals. In Computer Physics Communications (Vol. 179, Issues 1-3, pp. 61-65). https://doi.org/10.1016/j.cpc.2008.01.029 
27. Plimpton, S. (1995). for Short - Range Molecular Dynamics 1 Introduction. J.Computataional Physics, 117(June 1994), 1-42.

28. Rudyak, V. Y., \& Krasnolutskii, S. L. (2015). Simulation of the nanofluid viscosity coefficient by the molecular dynamics method. Technical Physics, 60(6), 798-804. https://doi.org/10.1134/S1063784215060237

29. Einstein, A. (1956). Investigations on the Theory of the Brownian Movement. Courier Corporation.

30. Brinkman, H. C. (1952). The viscosity of concentrated suspensions and solutions. The Journal of Chemical Physics, 20(4), 571.

31. Batchelor, G. K. (1977). The effect of Brownian motion on the bulk stress in a suspension of spherical particles. Journal of Fluid Mechanics, 83(1), 97-117.

32. Maron, S. H., \& Pierce, P. E. (1956). Application of Ree-Eyring generalized flow theory to suspensions of spherical particles. Journal of Colloid Science, 11(1), 80-95.

33. Cross, M. M. (1975). Viscosity-concentration-shear rate relations for suspensions. Rheologica Acta, 14(5), 402-403.

34.

White, F. M., \& Corfield, I. (2006). Viscous fluid flow (Vol. 3). McGraw-Hill New York. 


\section{Figures}
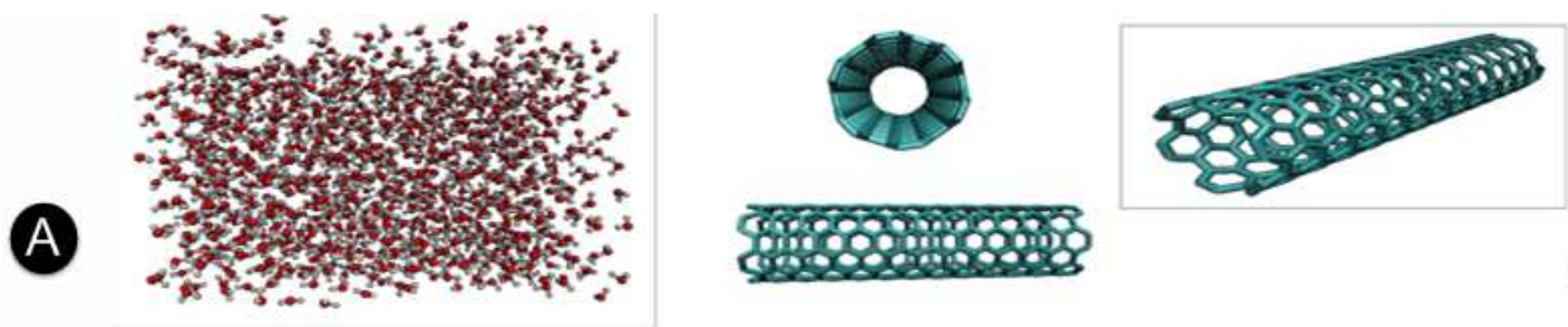

B

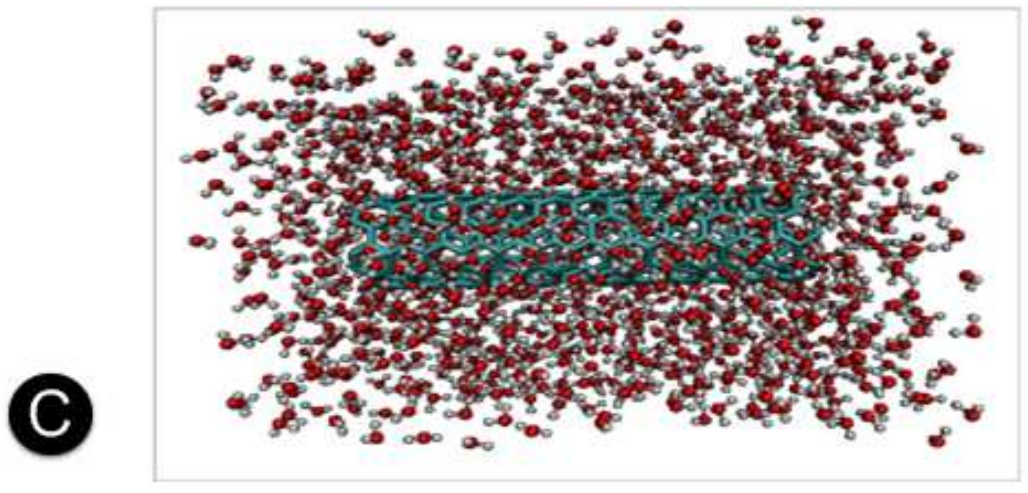

Figure 1

See the Manuscript Files section for the complete figure caption.

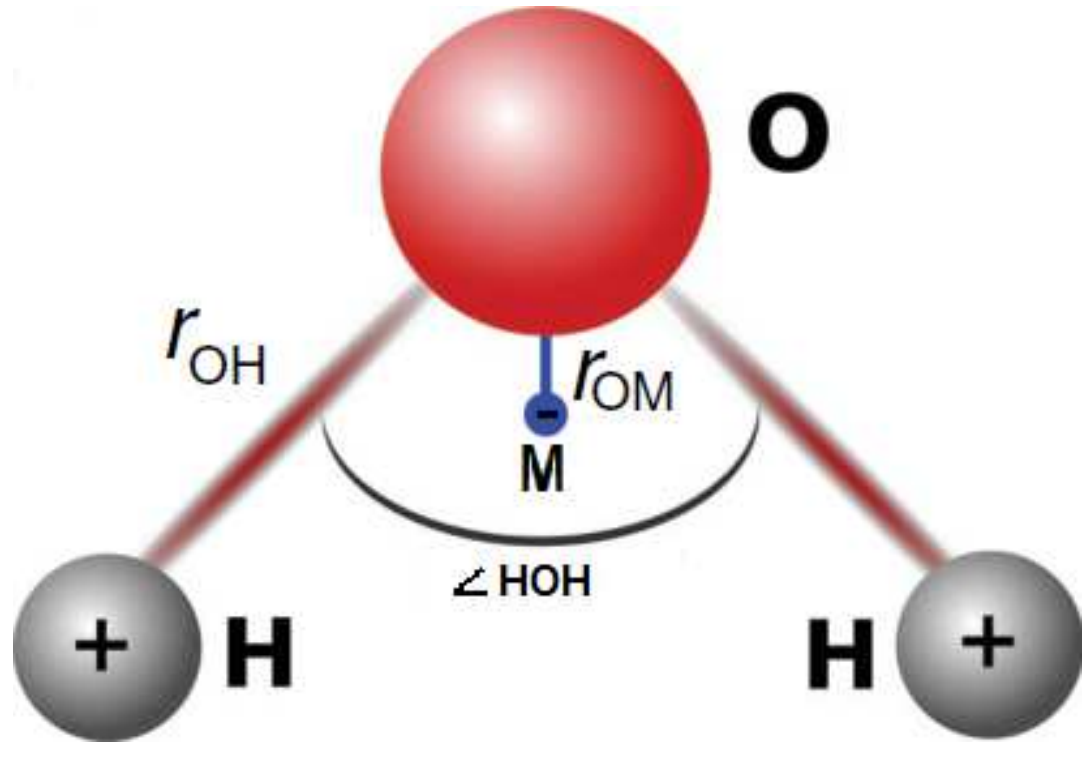

Figure 2

See the Manuscript Files section for the complete figure caption. 


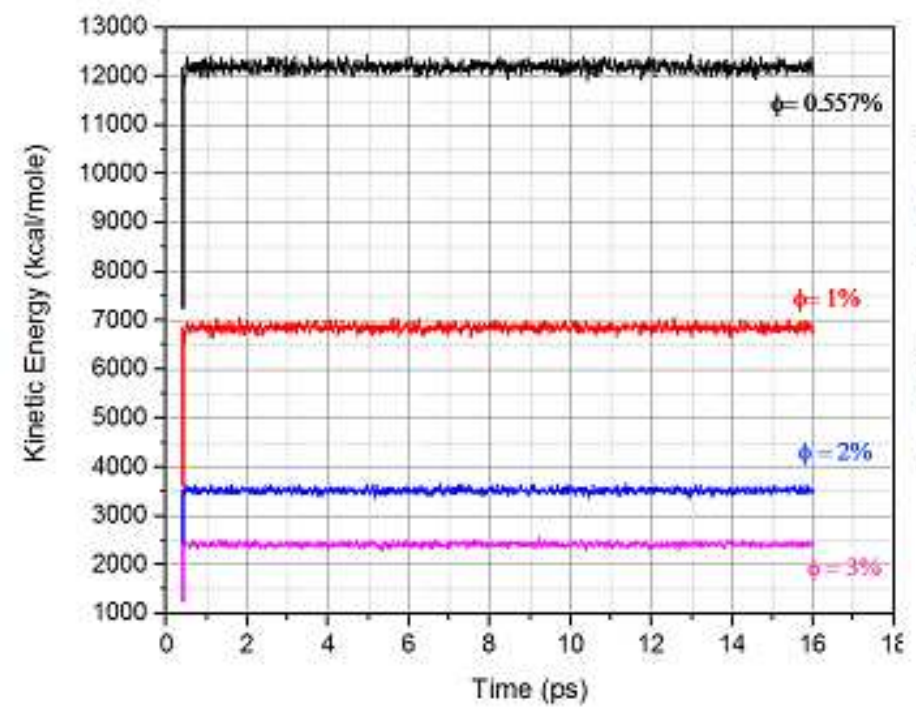

(a)

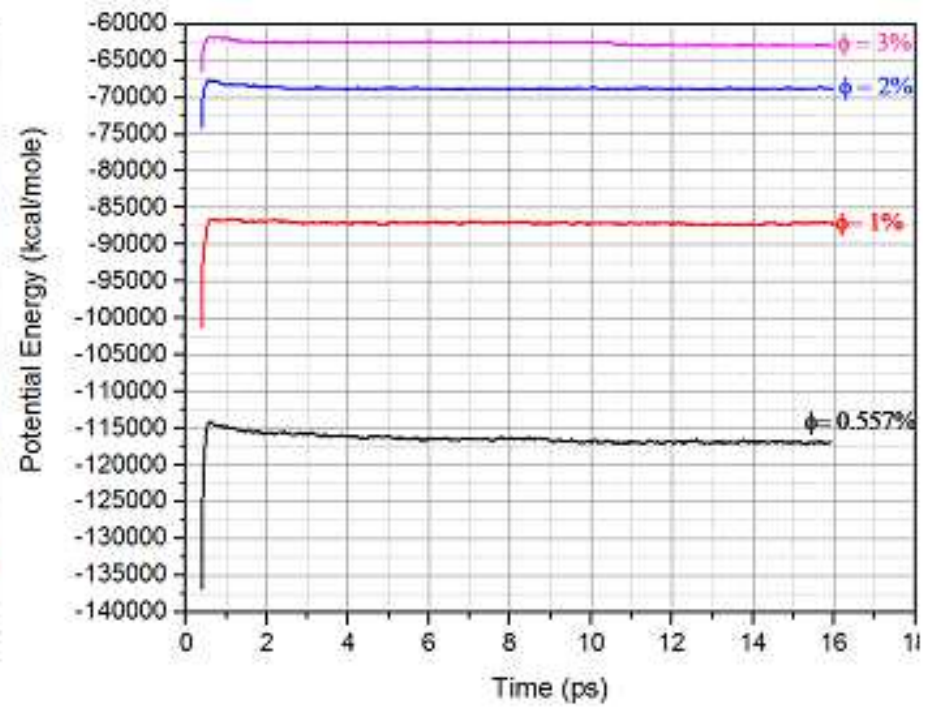

(b)

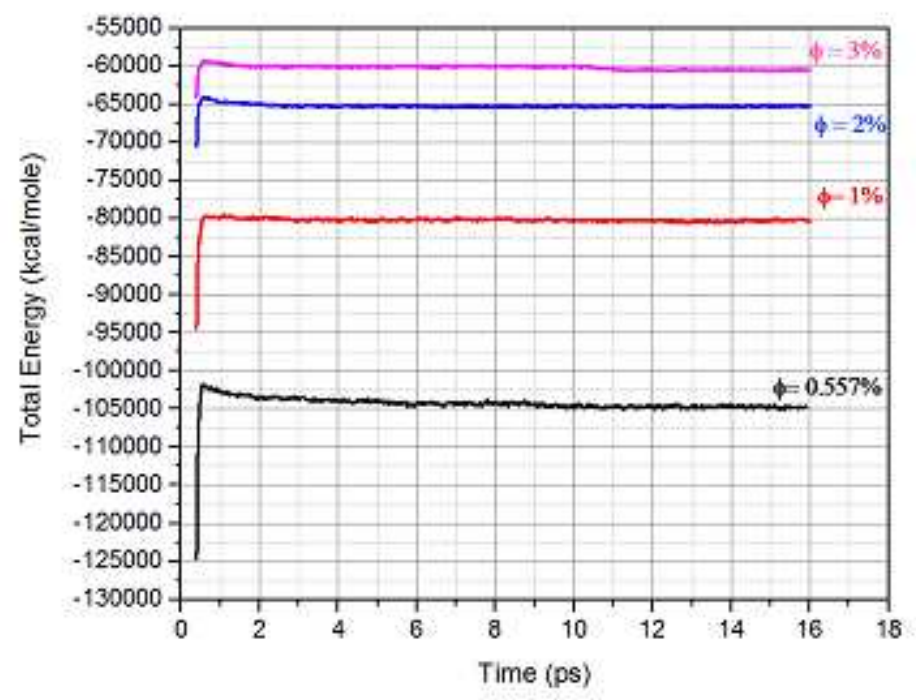

(c)

\section{Figure 3}

See the Manuscript Files section for the complete figure caption. 


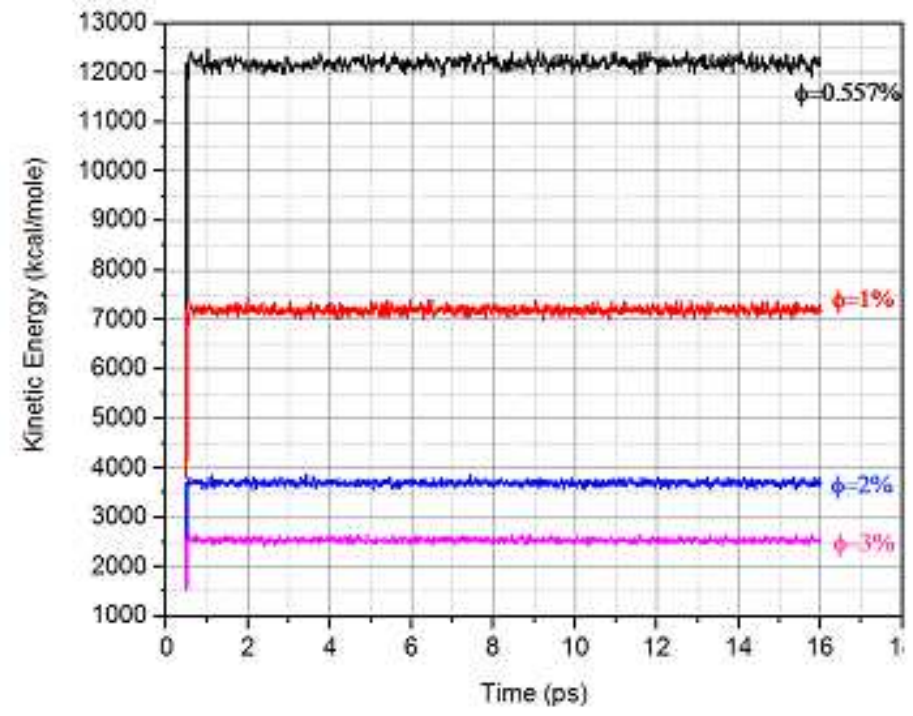

(a)

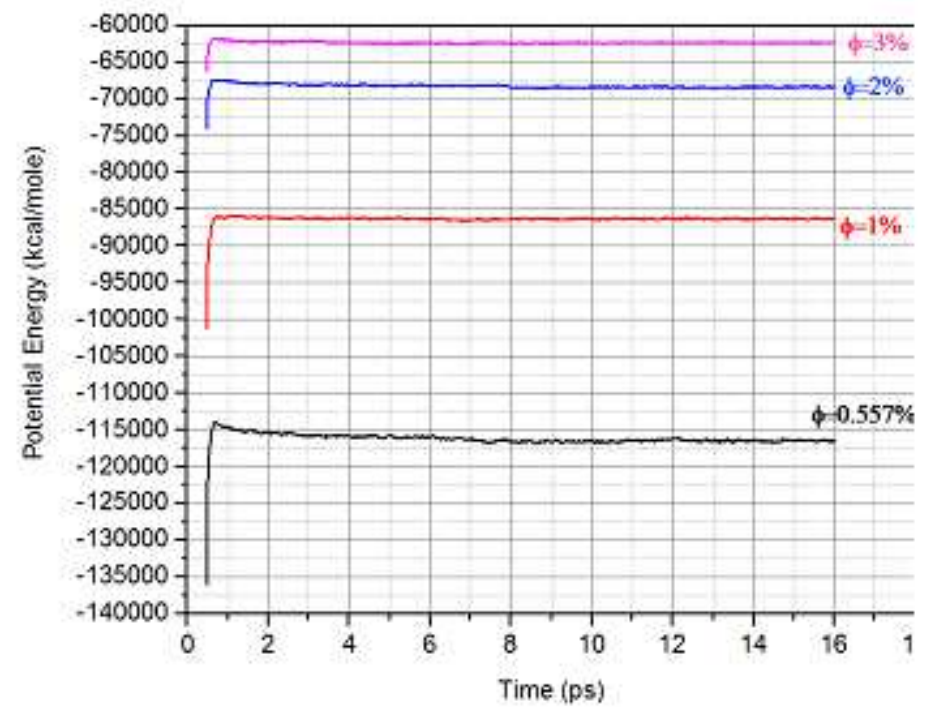

(b)

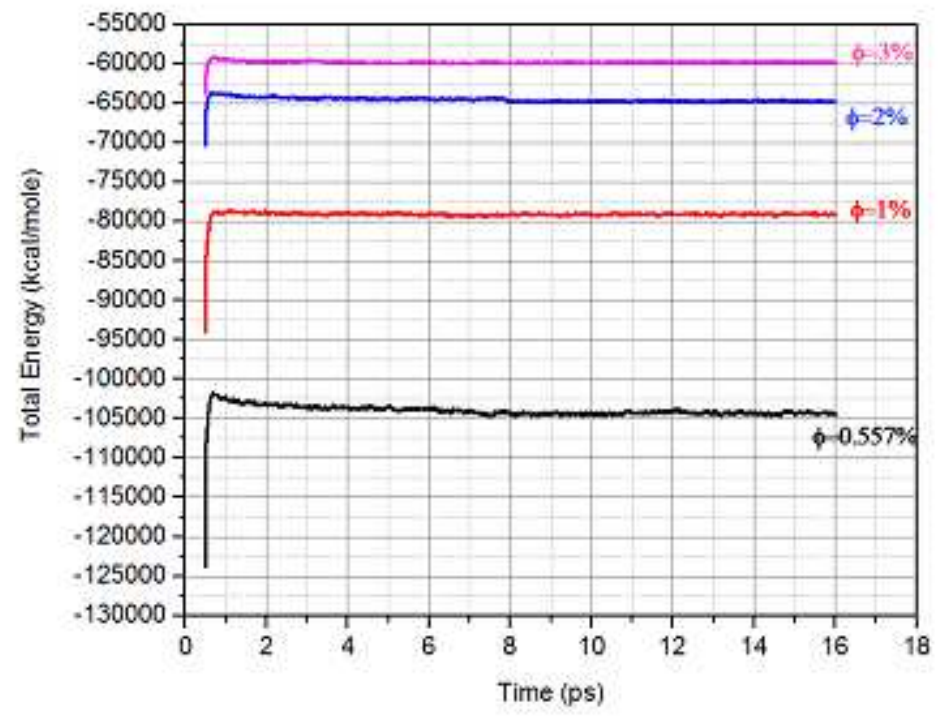

(c)

Figure 4

See the Manuscript Files section for the complete figure caption. 


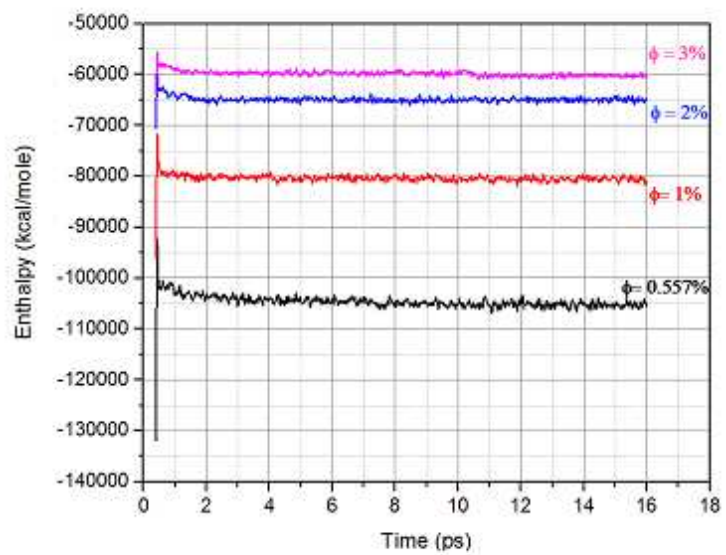

(a)
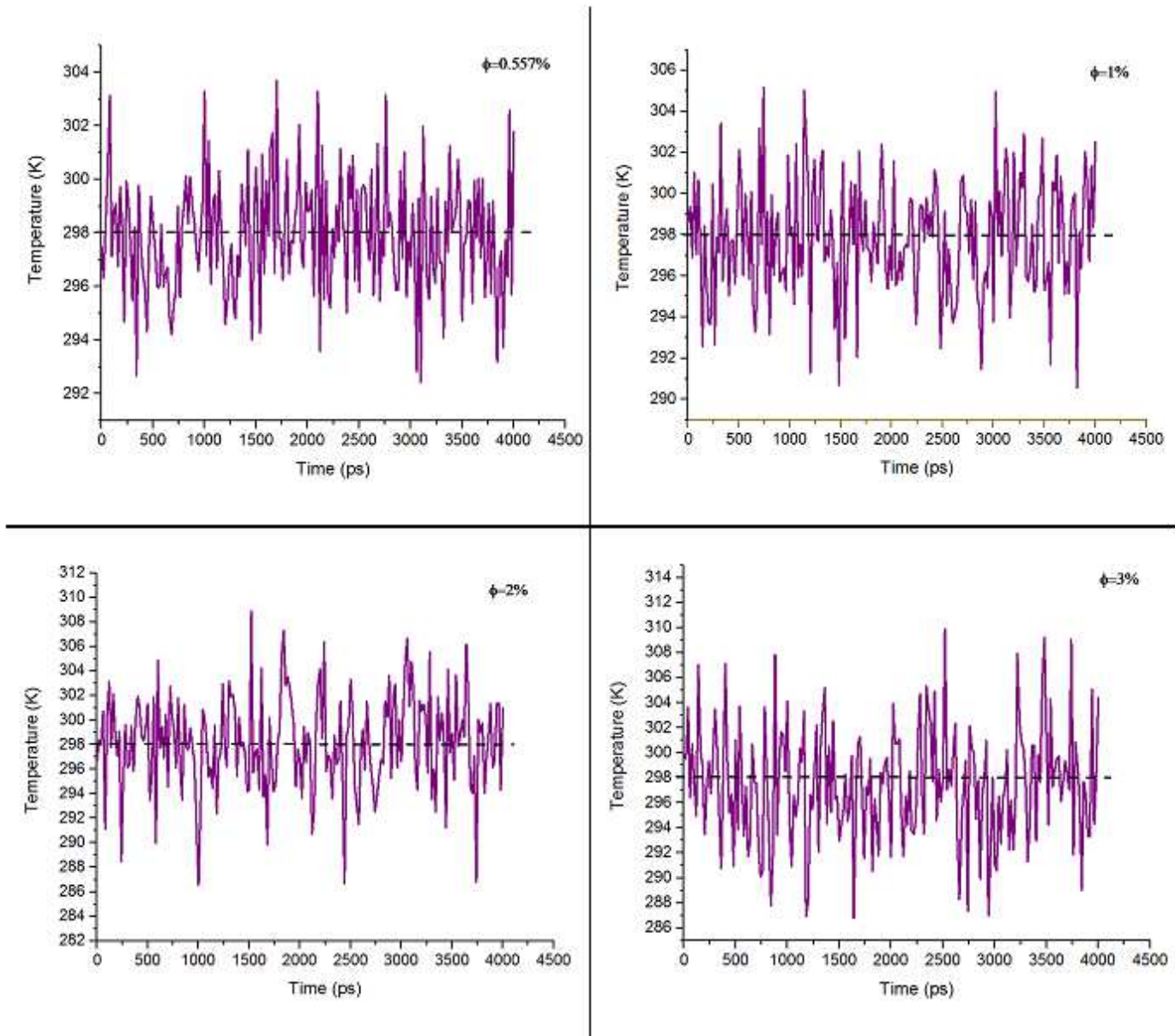

(b)

Figure 5

See the Manuscript Files section for the complete figure caption. 


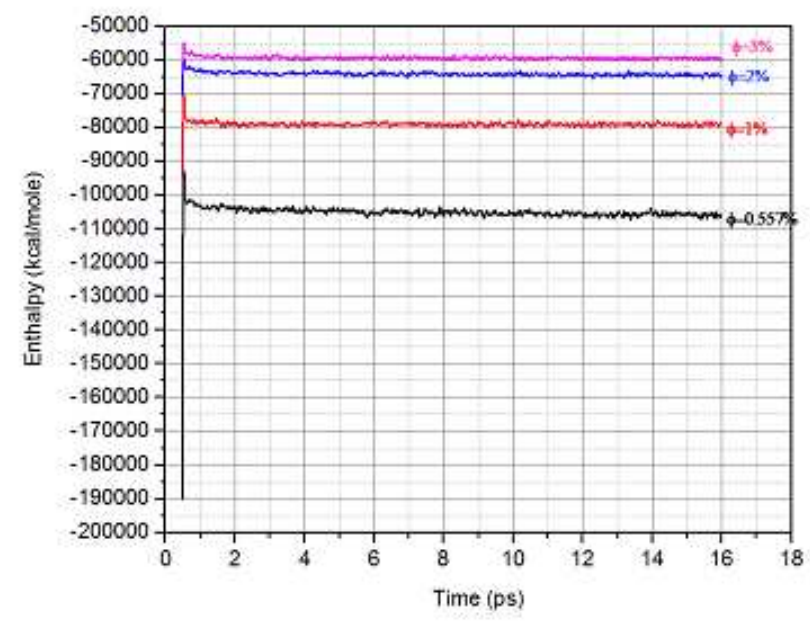

(a)
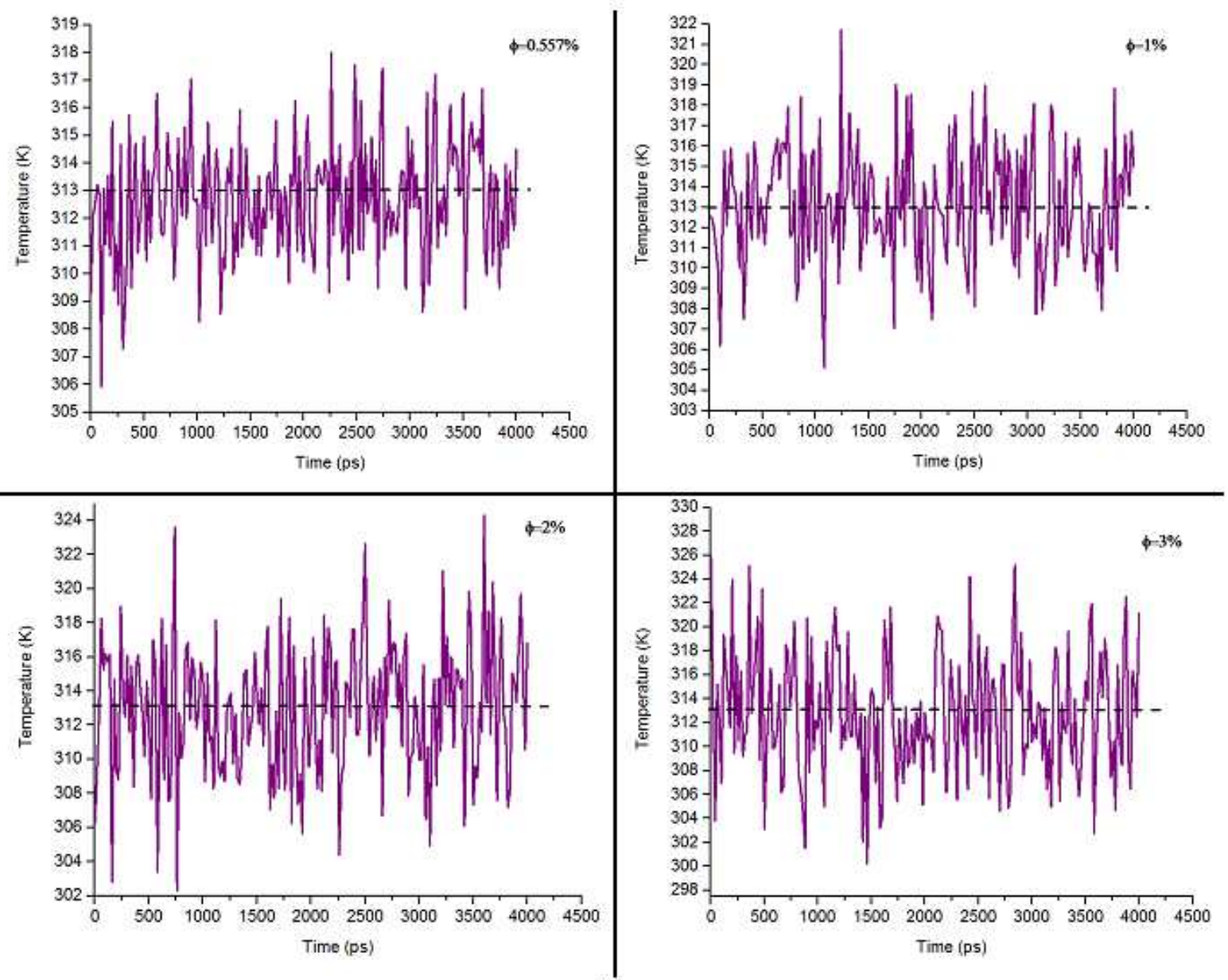

(b)

Figure 6

See the Manuscript Files section for the complete figure caption. 


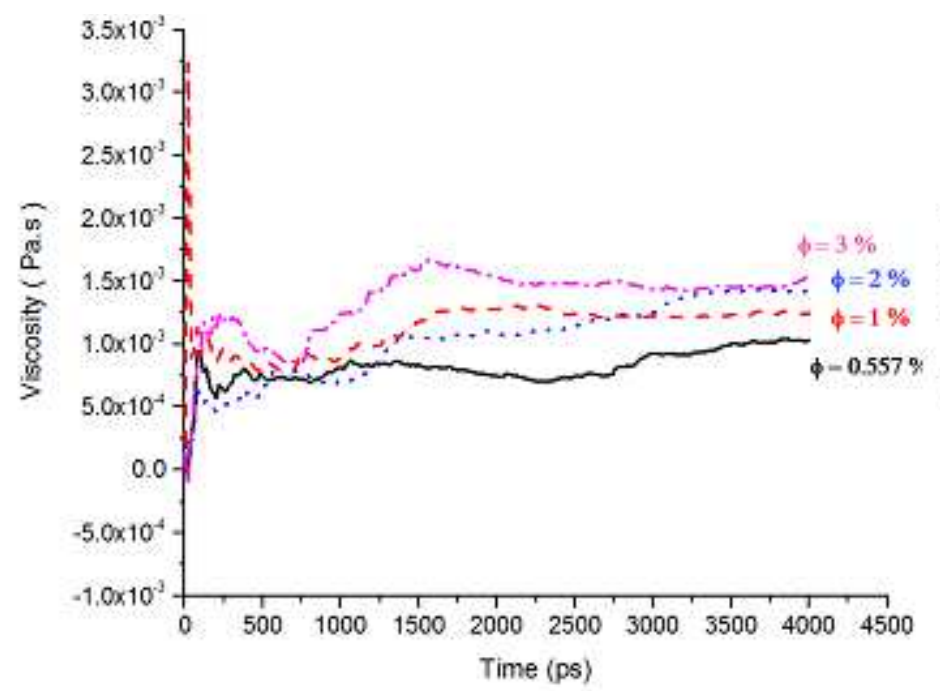

(a)

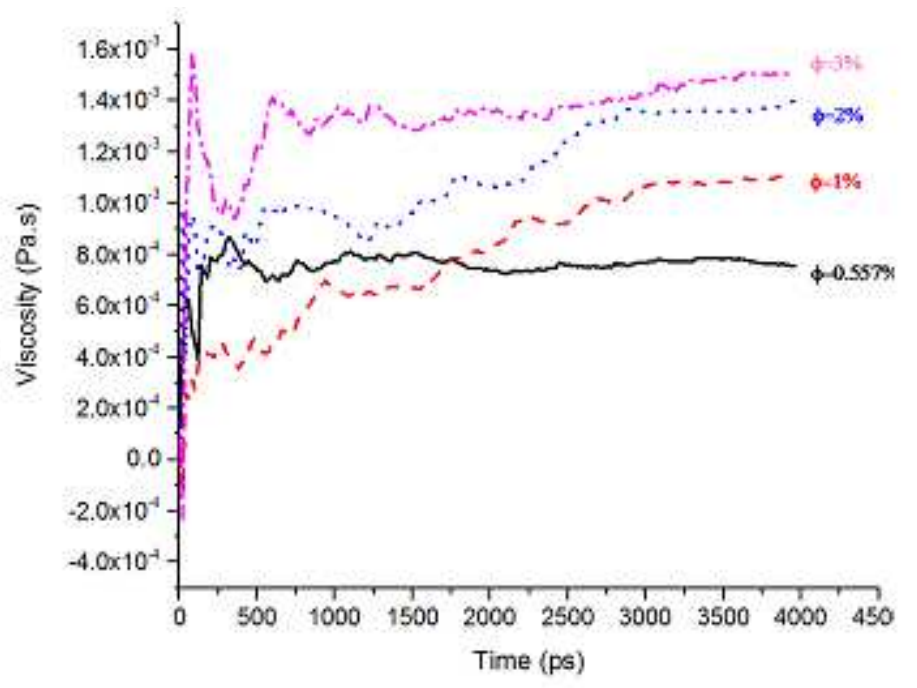

(b)

Figure 7

See the Manuscript Files section for the complete figure caption. 

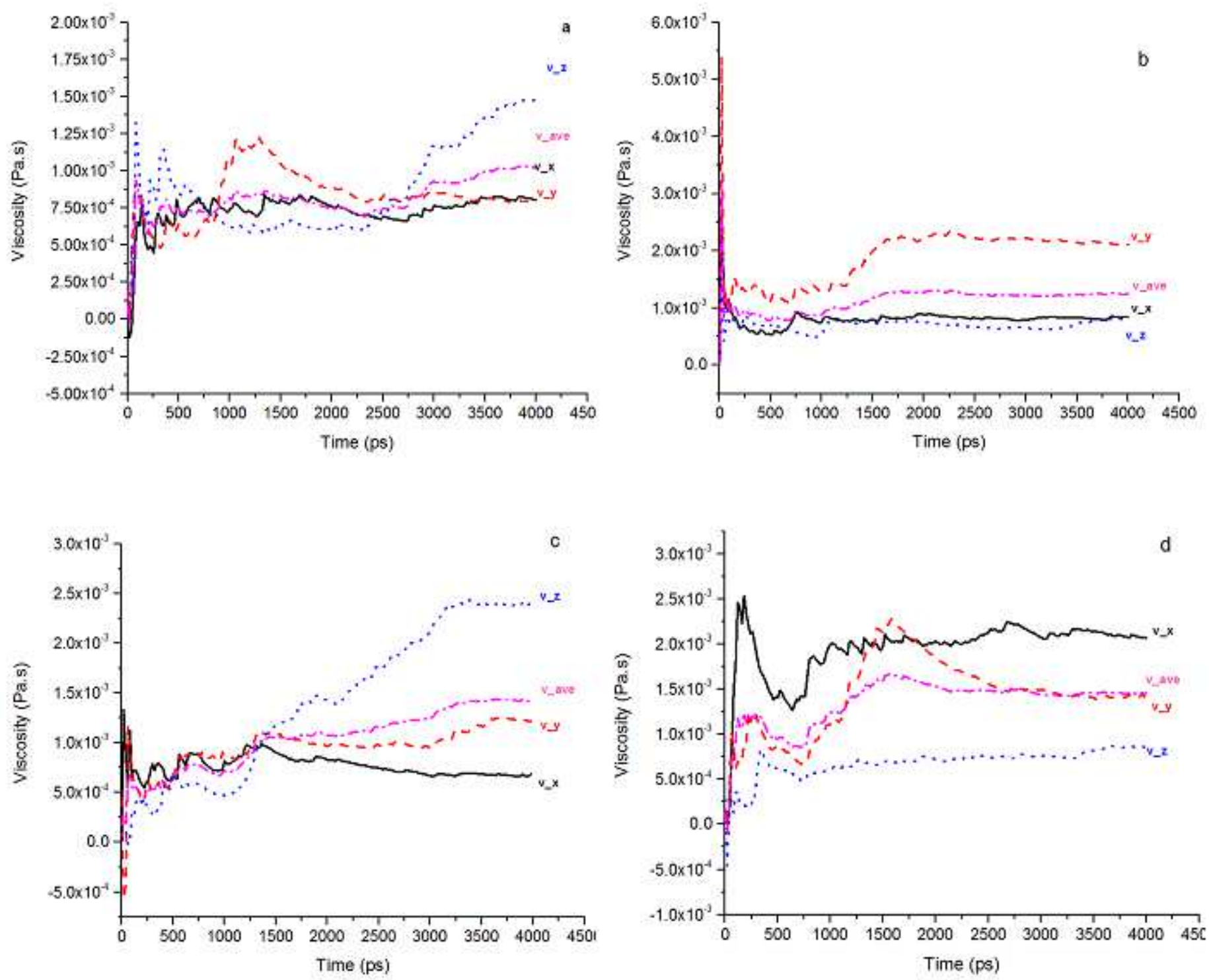

\section{Figure 8}

See the Manuscript Files section for the complete figure caption. 

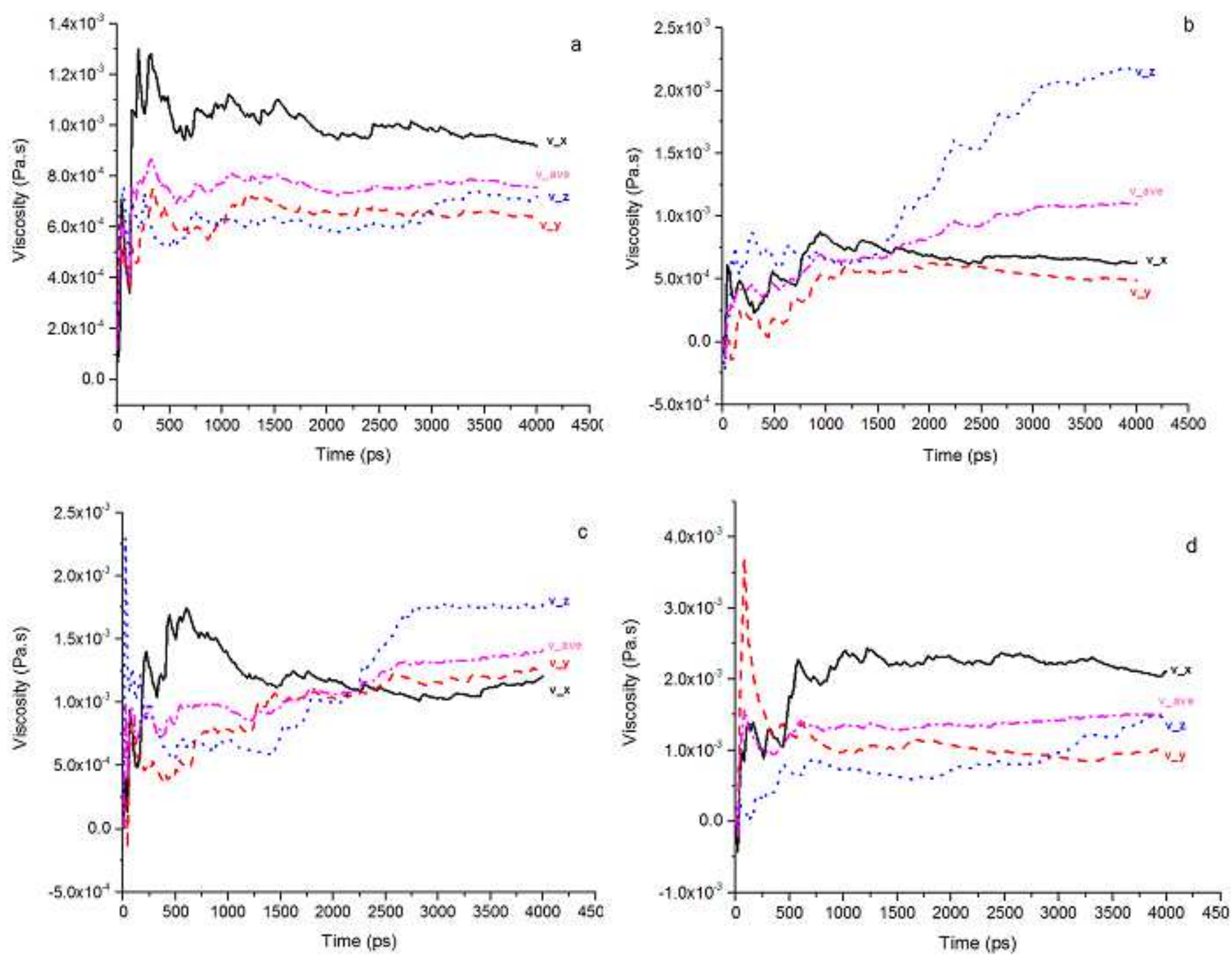

\section{Figure 9}

See the Manuscript Files section for the complete figure caption. 


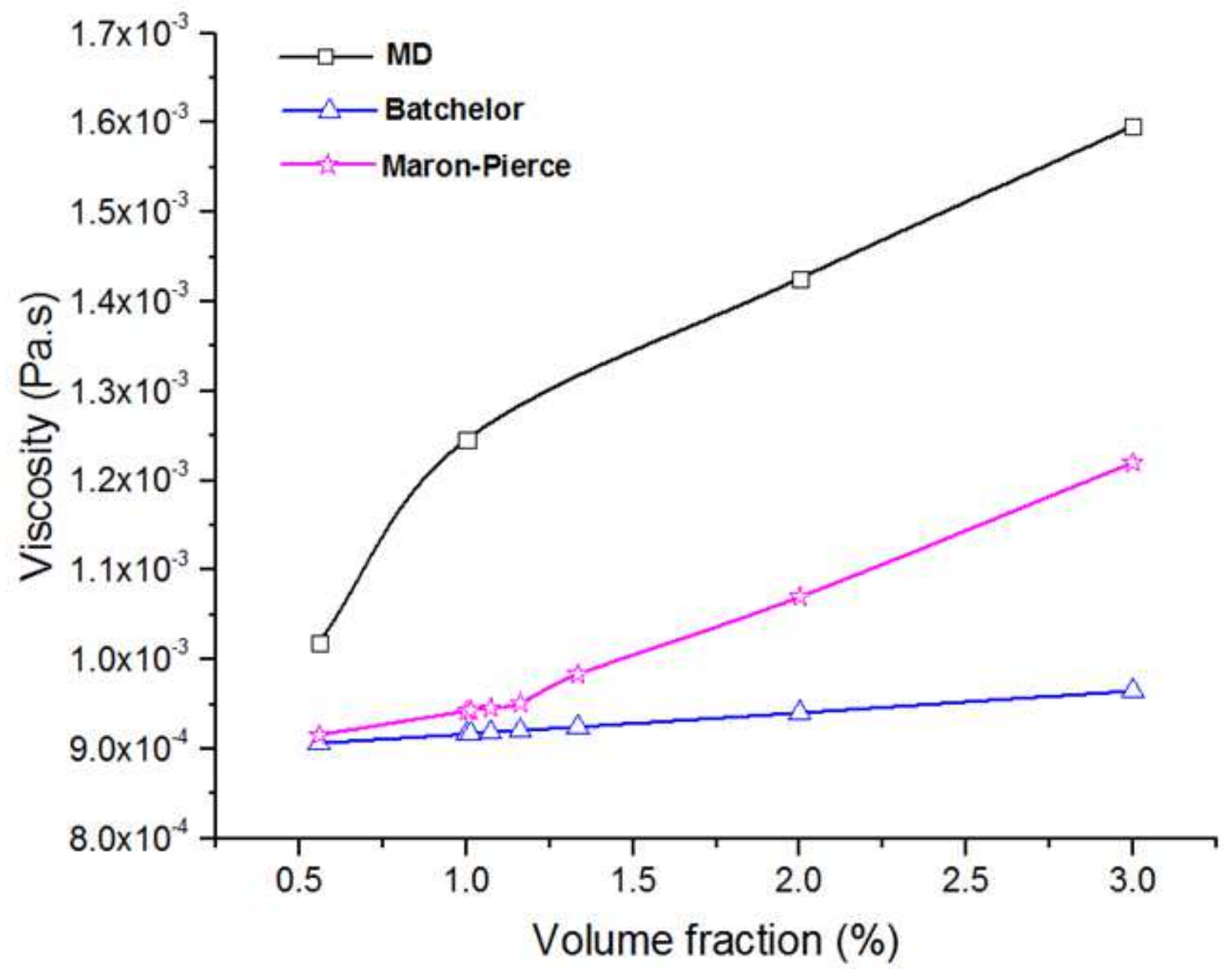

Figure 10

See the Manuscript Files section for the complete figure caption. 


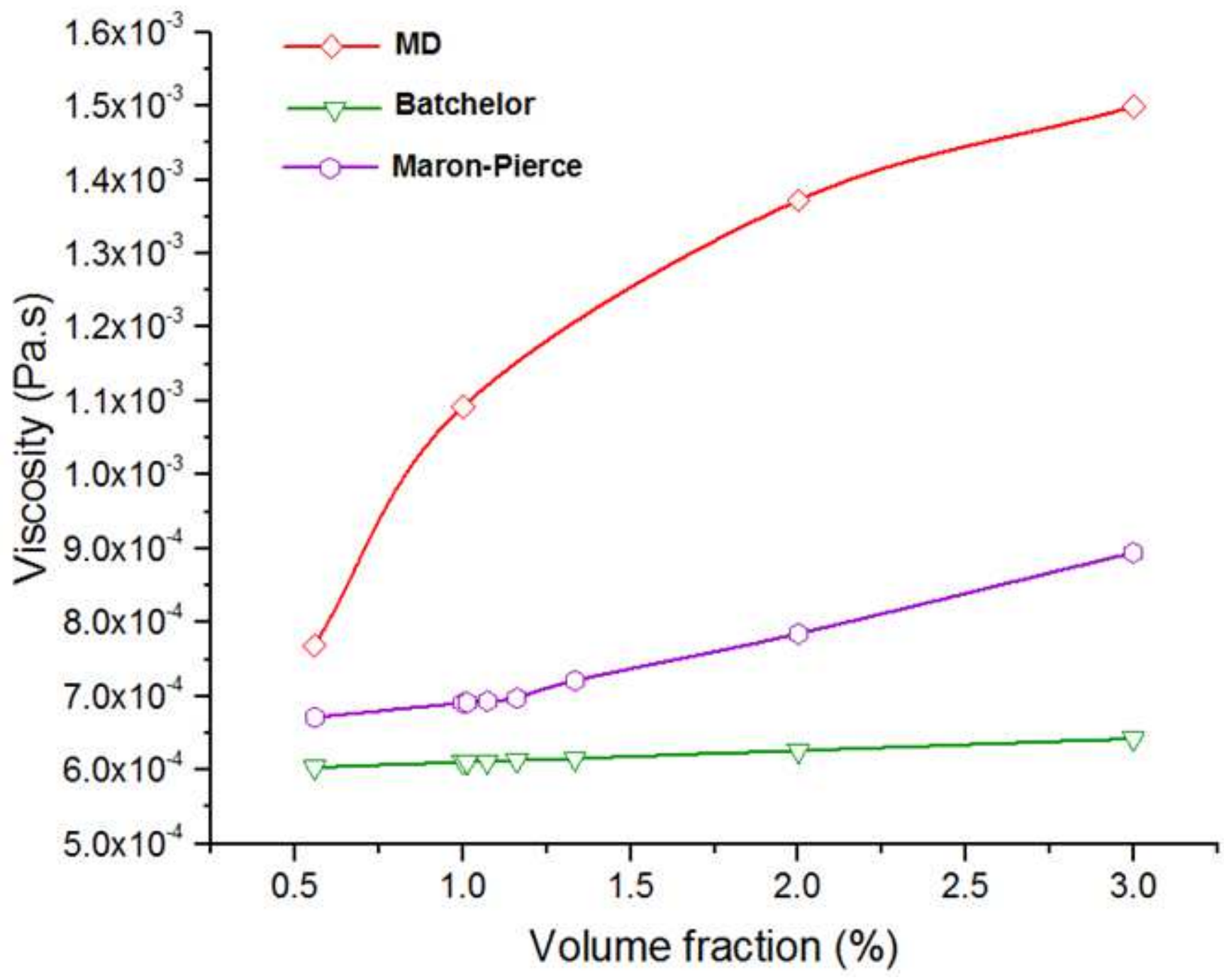

Figure 11

See the Manuscript Files section for the complete figure caption. 


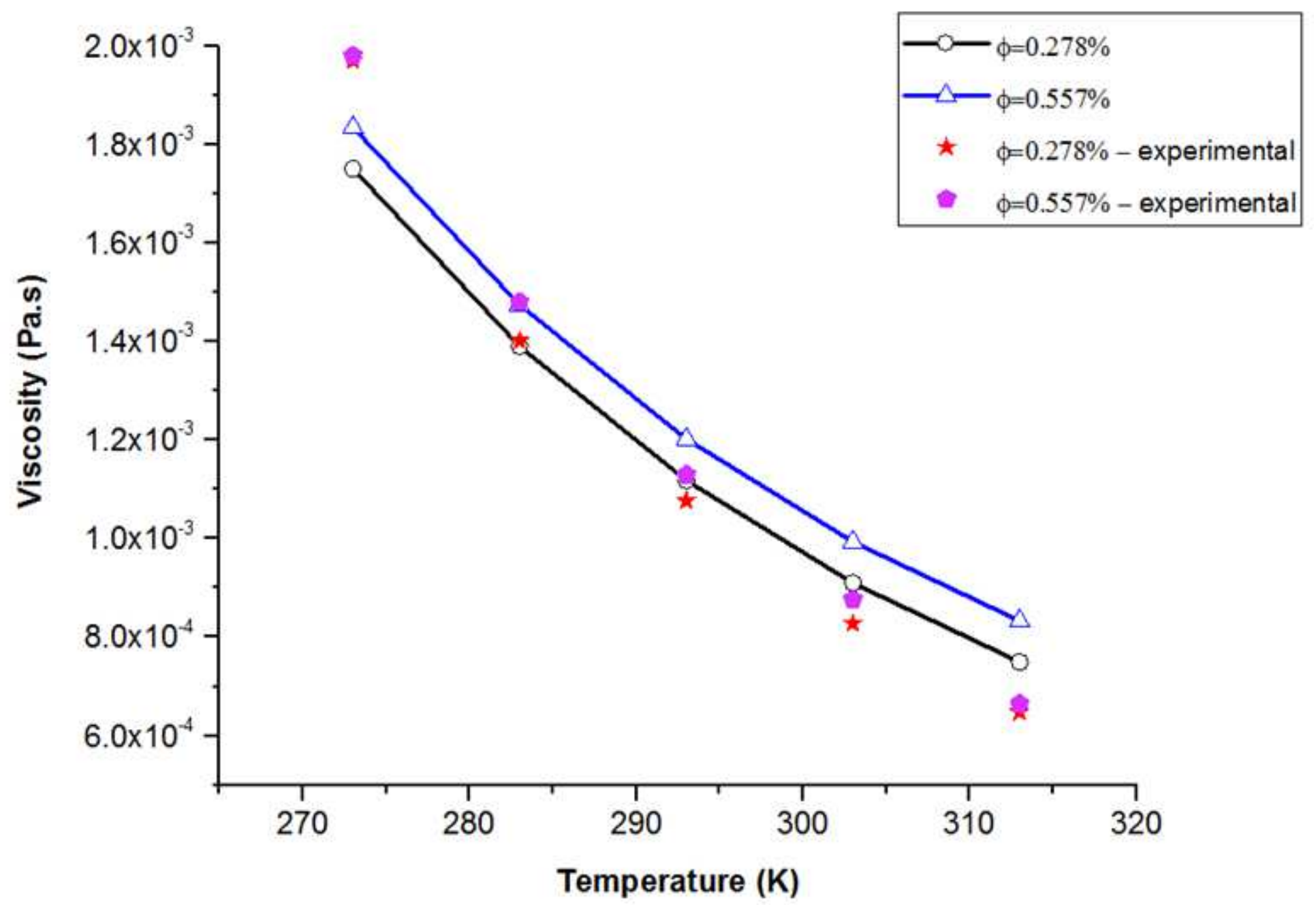

Figure 12

See the Manuscript Files section for the complete figure caption. 


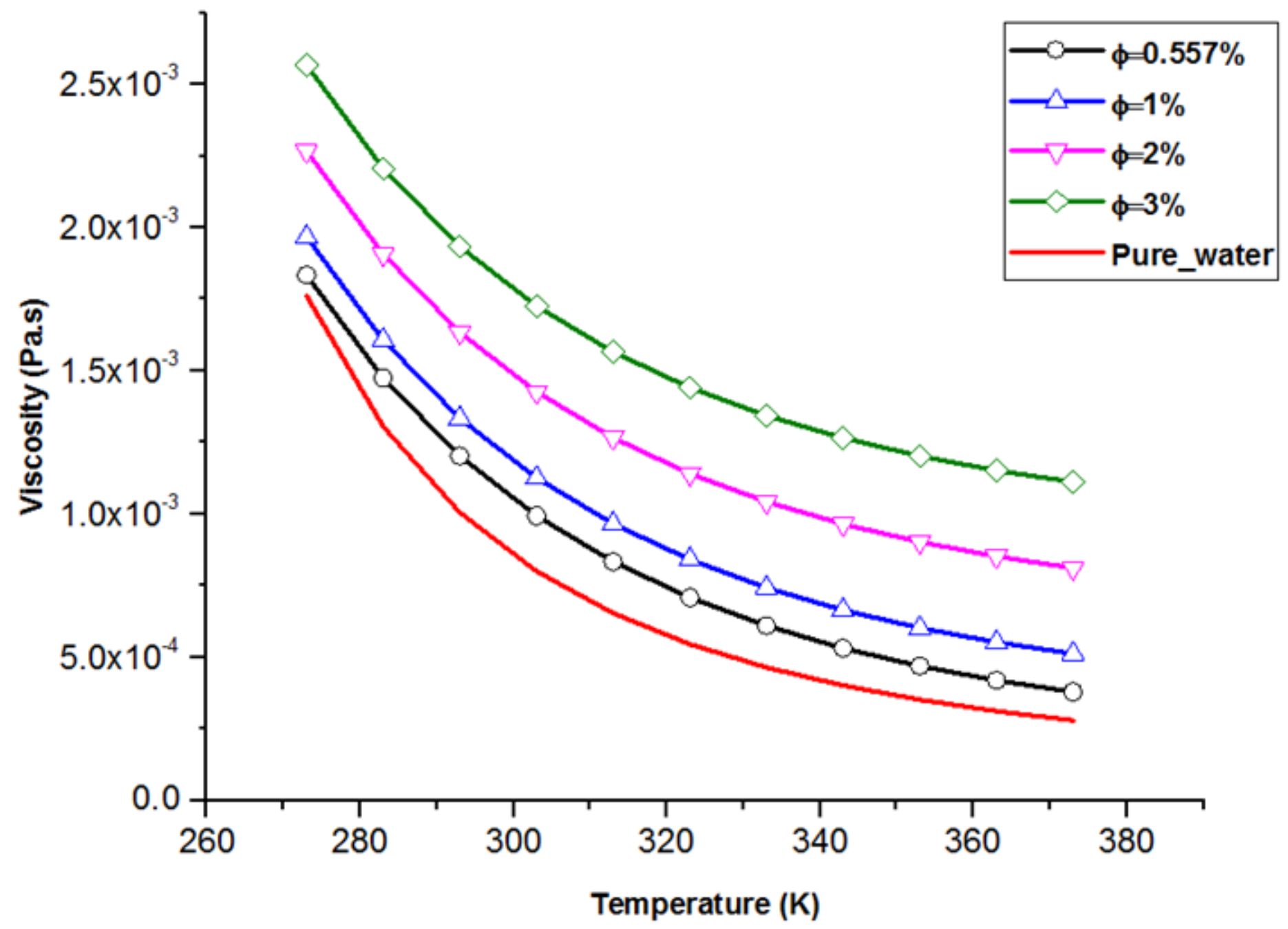

Figure 13

See the Manuscript Files section for the complete figure caption. 


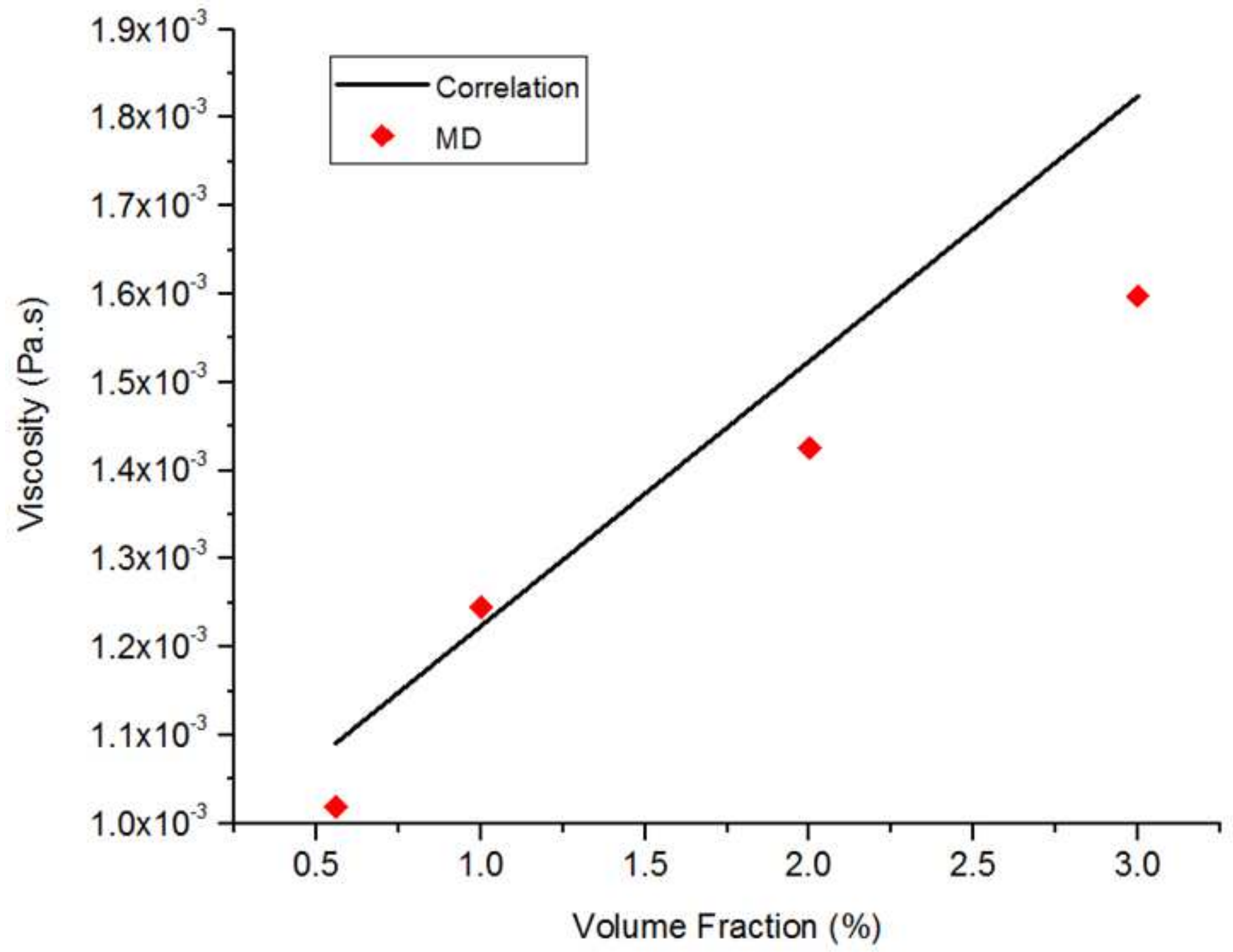

Figure 14

See the Manuscript Files section for the complete figure caption. 


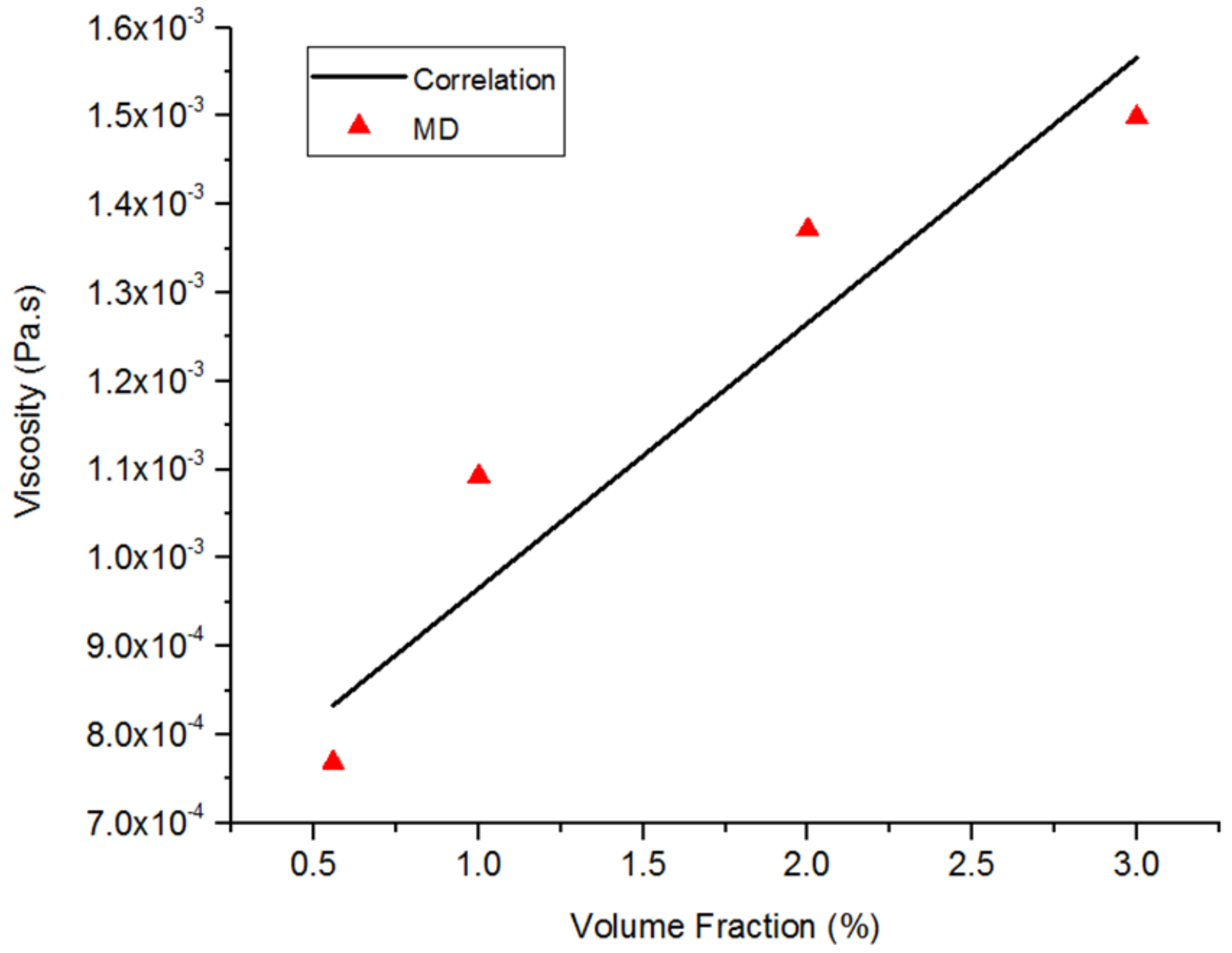

Figure 15

See the Manuscript Files section for the complete figure caption. 